
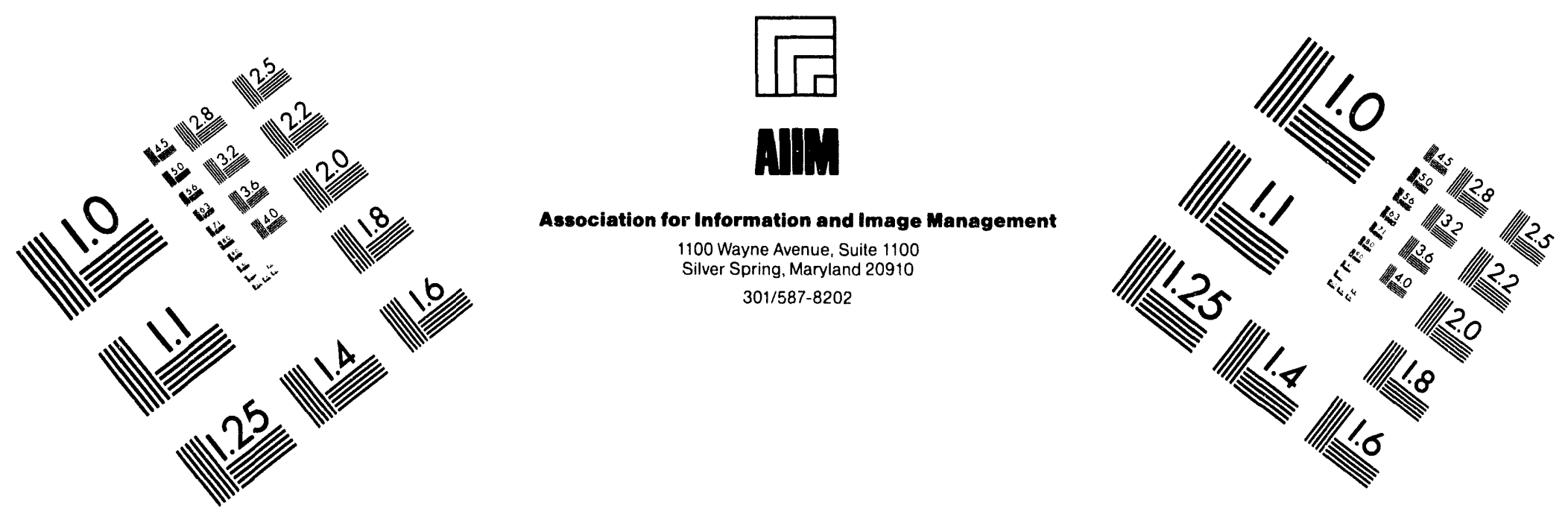

\title{
Centimeter
}

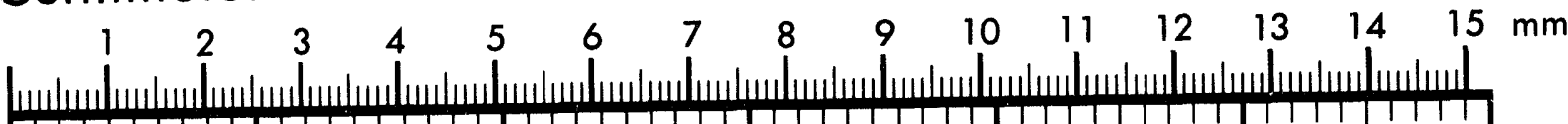
Tाग Inches
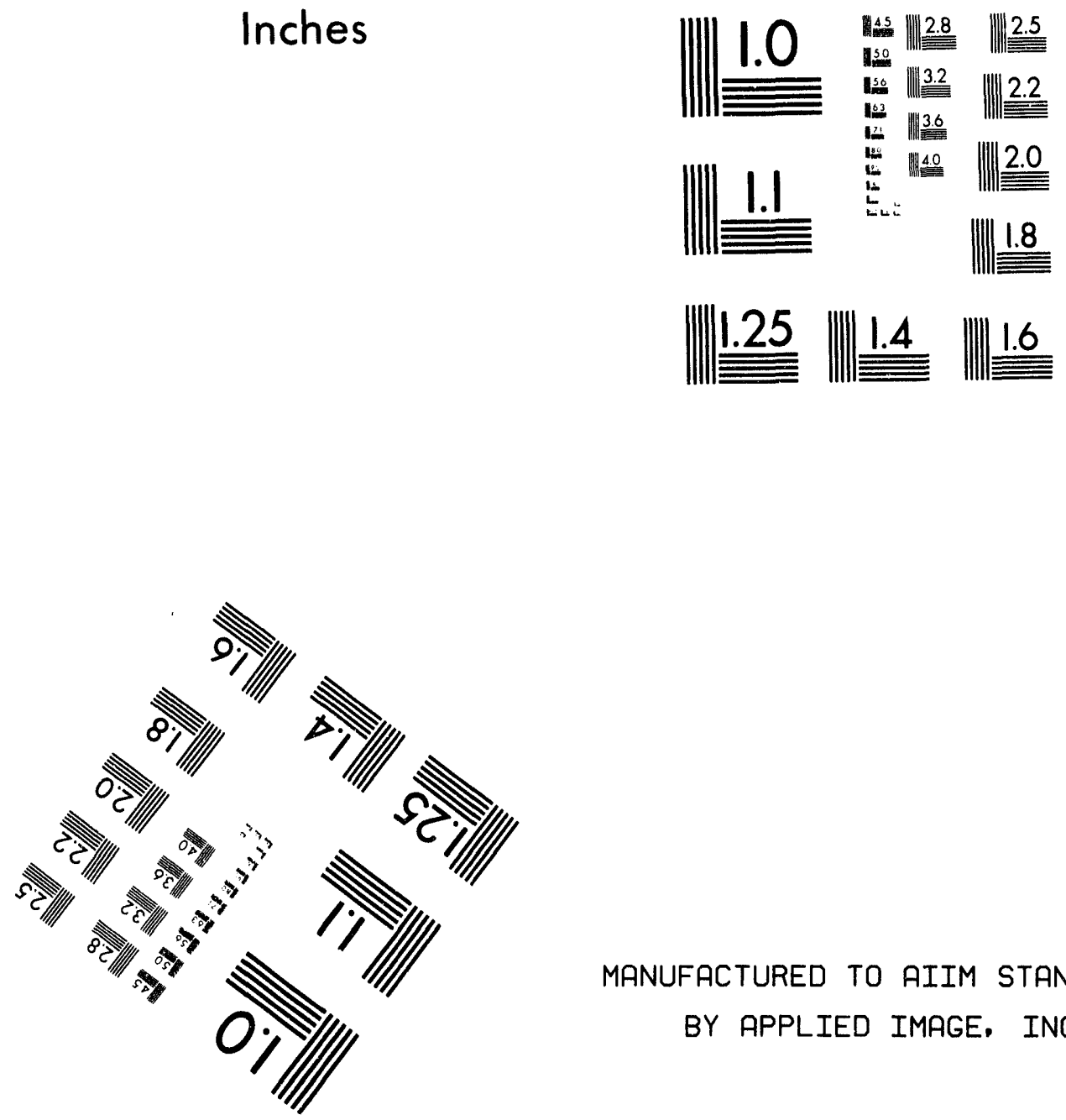

MANUFACTURED TO AIIM STANDARDS

BY APPLIED IMAGE. INC.

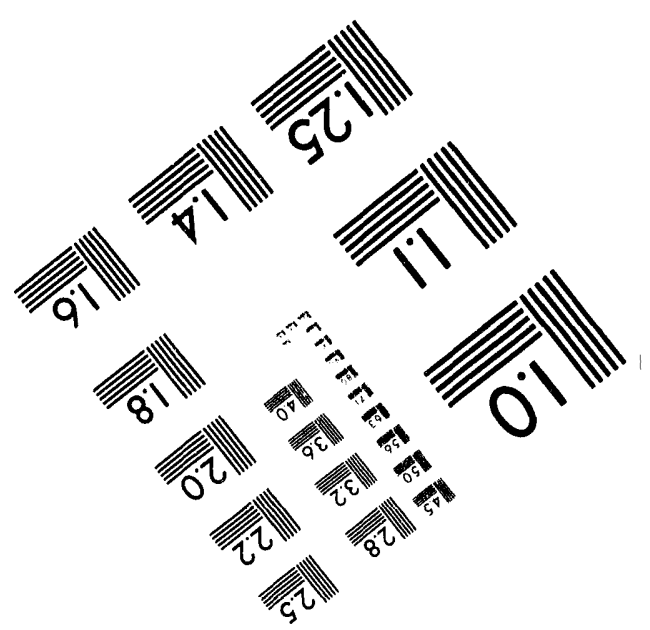



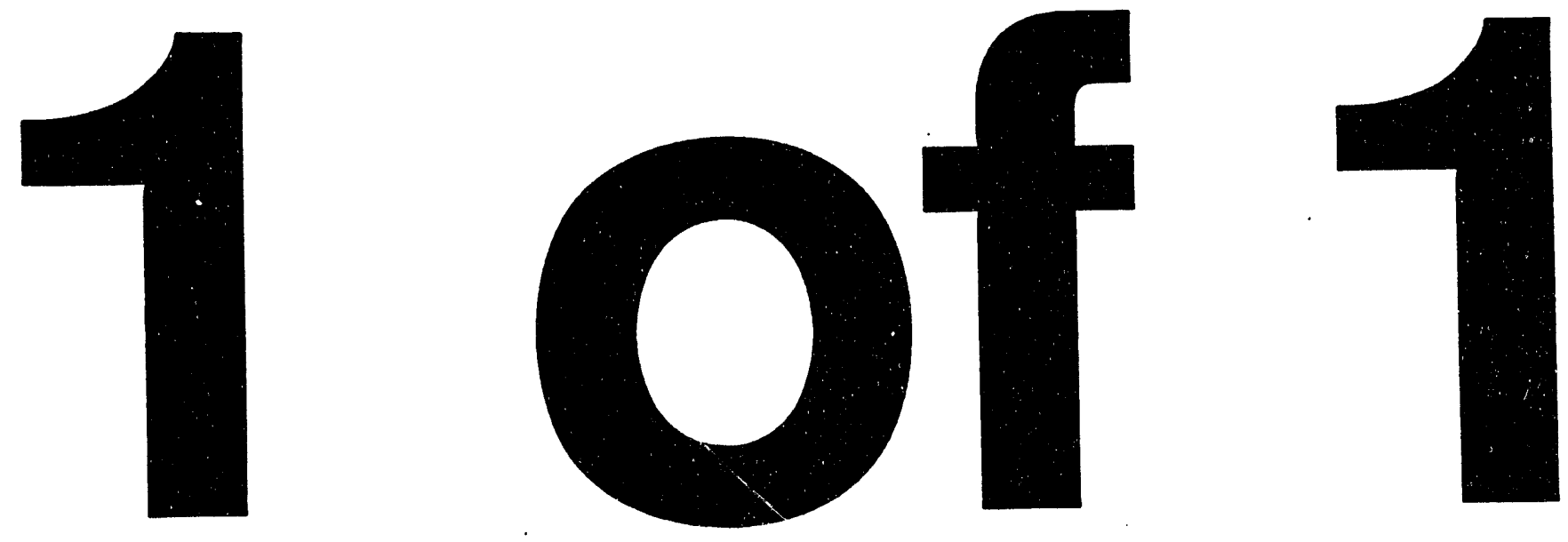
To:

Tank Waste Remediation Systems
From:

System Structural Integrity Asses sments

REV. 0

Project Title/Work Order:

\section{HANFORD SITE WASTE TANK FARM FACILITIES DESIGN RECONSTITUTION PROGRAM PLAN}

EDT No.: 607275

ECN No.:

\begin{tabular}{|c|c|c|c|c|}
\hline Name & MSIN & $\begin{array}{c}\text { With } \\
\text { Attachment }\end{array}$ & $\begin{array}{l}\text { EDT/ECN \& } \\
\text { Comment }\end{array}$ & $\begin{array}{c}\text { EDT/ECN } \\
\text { Only } \\
\end{array}$ \\
\hline D. R. Autery & $R 1-30$ & $x$ & & \\
\hline N. G. Awadalla & $\mathrm{R} 2-76$ & $x$ & & \\
\hline J. D. Bigbee & $\mathrm{R} 1-30$ & $x$ & & \\
\hline C. W. Dunbar & $R 1-30$ & $x$ & & \\
\hline D. B. Engelman & $\mathrm{R} 1-49$ & $x$ & & \\
\hline A. G. Hoffman & L4-89 & $x$ & & \\
\hline T. Laney & L4-89 & $x$ & & \\
\hline L. S. Legowik & L4-89 & $x$ & & \\
\hline T. Moleff & $R 1-30$ & $x$ & & \\
\hline R. E. Raymond & $R 2-54$ & $x$ & & \\
\hline J. G. Reder & L4-89 & $x$ & & \\
\hline K. V. Scott & $H 5-52$ & $x$ & & \\
\hline P. K. Shen & $\mathrm{HO}-39$ & $x$ & & \\
\hline R. R. Stickney & $R 1-49$ & $x$ & & \\
\hline J. D. Thomson & $\mathrm{R} 2-76$ & $x$ & & \\
\hline J. M. Vann & HO-39 & $x$ & & \\
\hline F. R. Vollert & $H 5-52$ & $x$ & & \\
\hline W. R. Weir & $L 4-89$ & $x$ & & \\
\hline Central Files (Orig. +2 copies) & L8-04 & $x$ & & \\
\hline OSTI (2) & L8-07 & $x$ & & \\
\hline $\begin{array}{l}\text { Station } 21 \\
\text { LDM }\end{array}$ & $\begin{array}{r}1+5-51 \\
1+4-17\end{array}$ & & & $x$ \\
\hline
\end{tabular}


SEP Ob 1994

35 station 21

\begin{tabular}{|c|c|c|}
\hline $\begin{array}{l}\text { 2. To: (Receiviry Organization) } \\
\text { Tank Waste Remediation } \\
\text { Systems }\end{array}$ & $\begin{array}{l}\text { 3. From: (originating organization) } \\
\text { System Structural Integrity } \\
\text { Assessments }\end{array}$ & $\begin{array}{l}\text { 4. Related EDT No.: } \\
\text { N/A }\end{array}$ \\
\hline $\begin{array}{l}\text { 5. Proj./Prog./Dept./Div.: } \\
\text { TWRS }\end{array}$ & $\begin{array}{l}\text { 6. Cog. Engr.: } \\
\text { F. R. Vollert }\end{array}$ & $\begin{array}{r}\text { 7. Purchase Order No.: } \\
N / A\end{array}$ \\
\hline \multicolumn{2}{|l|}{ 8. Originator Remarks: } & $\begin{array}{l}\text { 9. Equip./Component No.: } \\
N / A\end{array}$ \\
\hline \multicolumn{2}{|l|}{ APPROVAL/RELEASE } & $\begin{array}{c}\text { 10. System/Bldg./Facility: } \\
N / A\end{array}$ \\
\hline \multirow[t]{3}{*}{ 11. Receiver Remarks: } & & $\begin{array}{r}\text { 12. Major Assm. Dwg. No.: } \\
\text { N/A }\end{array}$ \\
\hline & & $\begin{array}{l}\text { 13. Permit/Permit Application No.: } \\
\text { N/A }\end{array}$ \\
\hline & & $\begin{array}{l}\text { 14. Required Response Date: } \\
08 / 22 / 94\end{array}$ \\
\hline
\end{tabular}

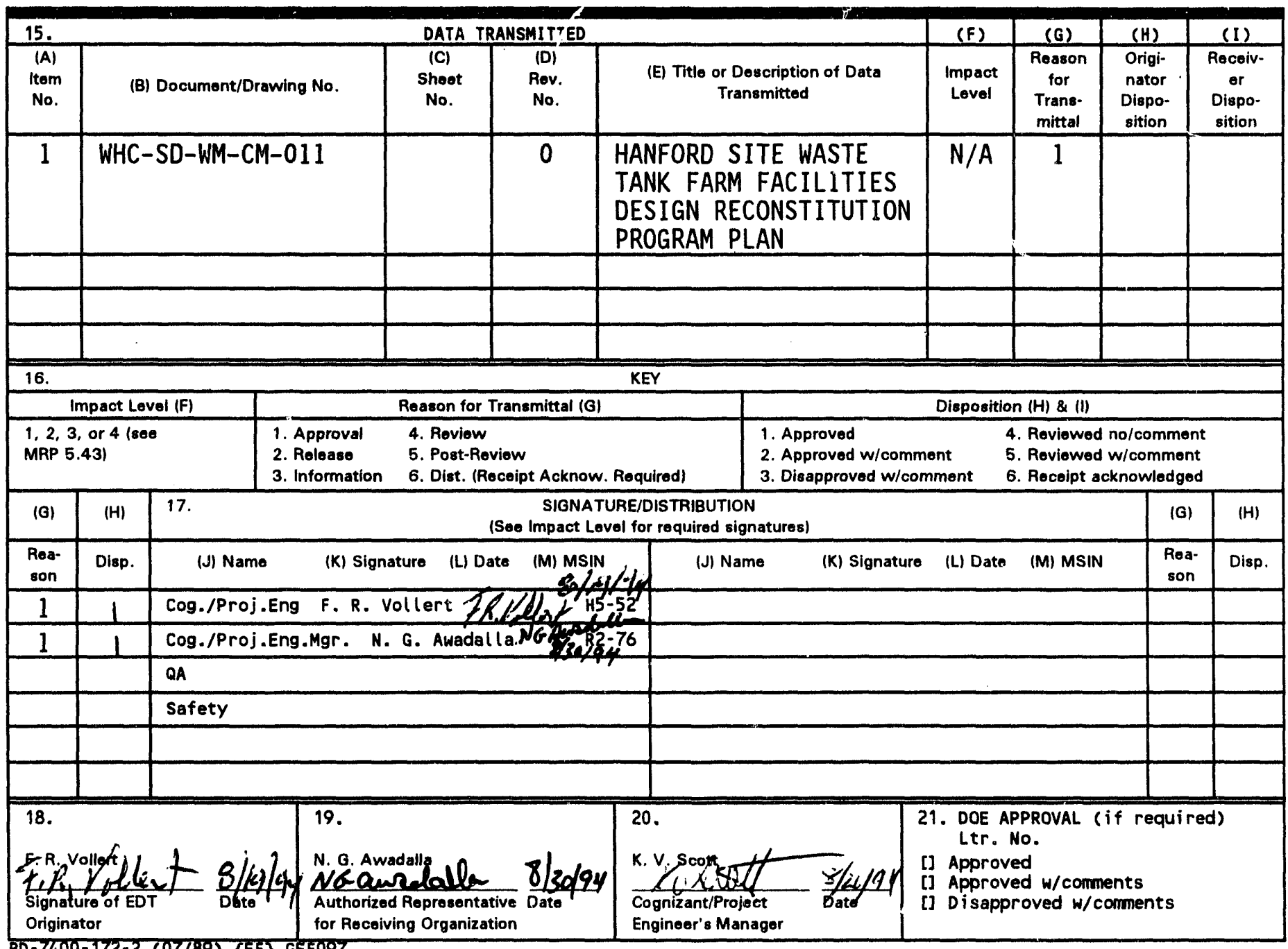




\section{RELEASE AUTHORIZATION}

\begin{tabular}{|ll}
\hline Document Number: & WHC-SD-WM-CM-011, Rev. 0 \\
\hline Document Title: & $\begin{array}{l}\text { Hanford Site Waste Tank Farm Facilities Design } \\
\text { Reconstitution Program Plan }\end{array}$ \\
\hline Release Date: & September 02, 1994 \\
\hline
\end{tabular}

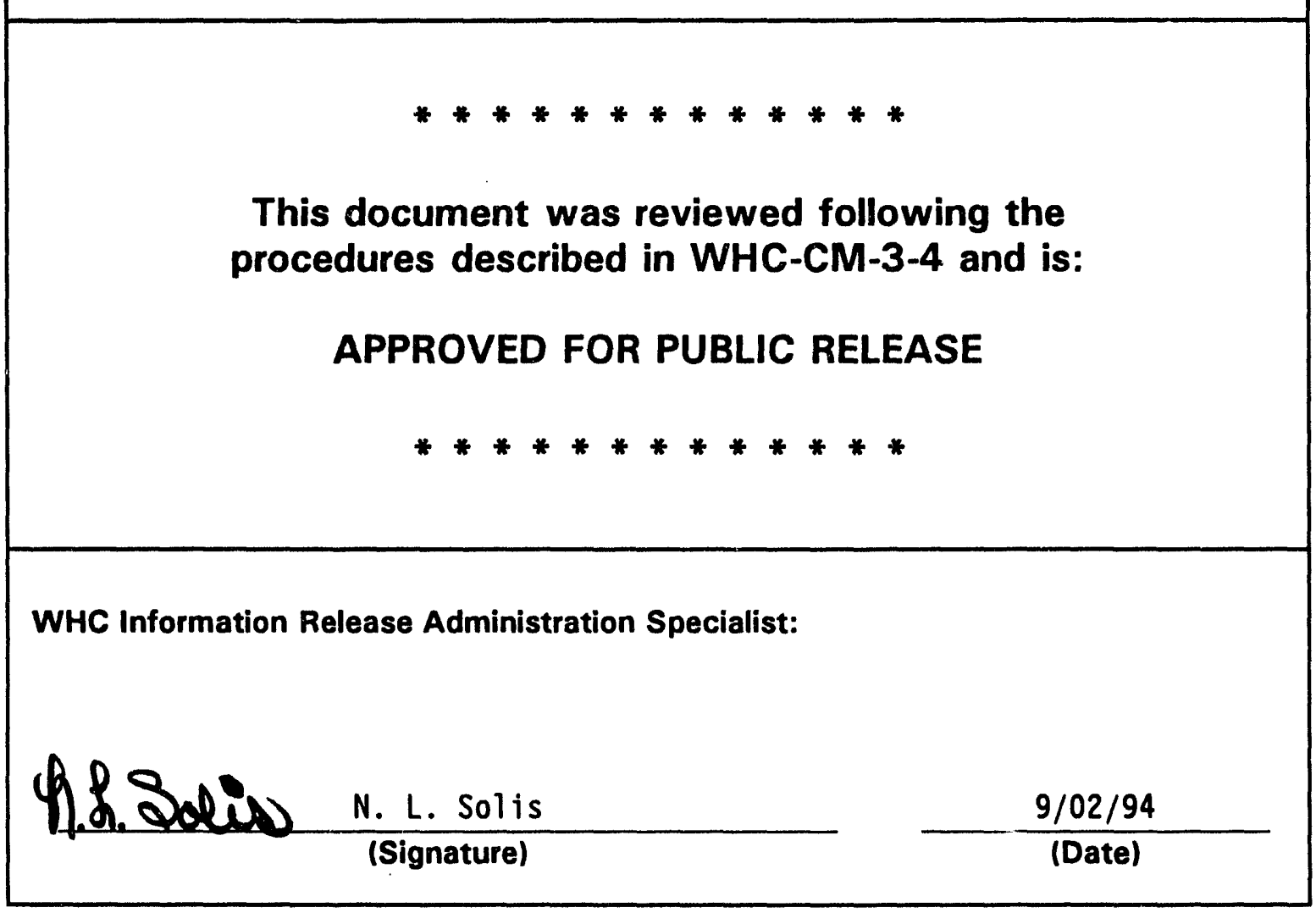




\section{SUPPORTING DOCUMENT}

2. Title

HANFORD SITE WASTE TANK FARM FACILITIES DESIGN RECONSTITUTION PROGRAM PLAN

\section{Key Hords}

Design Reconstitution, Design Information Summaries, Configuration Management, Waste Tank Farms and Systems, 242-A Evaporator

APPPOVED FOR
PUPL1G DE
7. Abstract
9.2 .94 फ. Soll

Westinghouse Electric Corporation, Nuclear Technology Division has provided technical information and other guidance for graded approach design reconst.itution planning and design information retrieval, documentation, and evaluation and regeneration for the waste tank farm facilities. This includes descriptions and outlines of the procedures that need to be developed to implement the design reconstitution program for the tank farms. The program objectives will include design information summaries (DIS) for the tank farm facilities, which correlate recovered design requirements and their bases. The DIS will be configuration management baselines conforming with the configuration management standard DOE-STD1073.

8. RURPOSE AND USE OF DOCUMEY - This dochnent was prepared fo use whin the U.S. Departmer? of Energy and ts contractors. Is to be uged only to pefform, direct, or integrate wo under U.S. De artment of Eng gy contracts. This acument is $n /$ approved for publ release urili reviewed.

PATENT STATO - Mis document copy, since it is transmitted in advance of pate clearance, is made available in onfidence solely for use in pe formance of work under cofitacts with the U.S. Departm it of torgy. This document is no to bubl ished nor its conten's otherwist disseminated or used fopos other than specified above before hatent approval for $s$ ch releas or use has been se,ured, upon reques. from the Patent ounsel, U.S. Department of Encrgy Field office, Richland, WA.

DISCLAIMER - This report was prepared as an account of work sponsored by an agency of the United States Government. Neither the United States Government nor any agency thereof, nor any of their employees, nor any of their contractors, subcontractors or their employees, makes any warranty, express or implied, or assumes any legal liability or responsibility for the accuracy, completeness, or any third party's use or the results of such use of any information, apparatus, product, or process disclosed, or represents that its use would not infringe privately owned rights. Reference herein to any specific commercial product, process, or service by trade name, trademark, manufacturer, or otherwise, does not necessarily constitute or imply its endorsement, recommendation, or favoring by the United States Government or any agency thereof or its contractors or subcontractors. The views and opinions of authors expressed herein do not necessarily state or reflect those of the United States Government or any agency thereof.

10. RELEASE STAMP

\section{CFFICIAL RELEASE BY inime \\ DATE SEP O 61994}

35 station 21 


\section{HANFORD SITE WASTE TANK FARM FACILITIES DESIGN RECONSTITUTION PROGRAM PLAN}

Contract Number 309367

August 3, 1994

Prepared for:

Westinghouse Hanford Company

P.O. Box 1970

Richland, Washington 99352

by

Raymond M. Malinchak, P.E.

Westinghouse Electric Corporation
Nuclear Technology Division
Post Office Box 355
Pittsburgh, Pennsylvania $15230-0355$ 


\section{EXECUTIVE SUMMARY}

Throughout the commercial nuclear industry the lack of design $r$ sonstitution programs prior to the mid 1980's has resulted in inadequate documentation to support operating facilities configuration changes or safety evaluations. As a result, many utilities have completed or have ongoing design reconstitution programs and have discovered that without sufficient pre-planning their program can be potentially very expensive and may result in end-products inconsistent with the facility needs or expectations.

Recognizing the commercial nuclear industry and government nuclear facility experiences with inadequate configuration and design documentation ("lessons learned"), the U. S. Department of Energy (DOE) issued in November 1993 a standard (DOE-STD-1073-93) for guidelines that prescribe good configuration management practices for DOE operating facilities. These guidelines were crafted to address weaknesses known to exist at DOE nuclear facilities as confirmed by various reports.

A design reconstitution program plan is developed here for the Hanford waste tank farms facility as a consequence of the DOE Standard on operational configuration management. Part of this Standard provides guidance for the development and implementation of a design reconstitution program including objectives, criteria, and a graded approach strategy. This design reconstitution program is subordinate to the Waste Tank Farms and the 242-A Evaporator Configuration Management Plan

This design reconstitution plan conforms with the DOE Standard guidelines as applied to the Hanford waste tank farms and their operating ancillary systems, including the evaporator. This plan provides for the recovery or regeneration of design requirements and basis, the compilation of Design Information Summaries, and a methodology to disposition items open for regeneration that were discovered during the development of Design Information Summaries. Implementation of this plan will culminate in an endproduct of about 30 Design Information Summary documents. These documents will be developed to identify tank farms facility design requirements and design bases and thereby capture the technical baselines of the facility.

This plan identifies the methodology necessary to systematically recover documents that are sources of design input information, and to evaluate and disposition open items or regeneration items discovered during the development of the Design Information Summaries or during the verification and validation processes. These development activities will be governed and implemented by three procedures and a guide that are to be developed as an outgrowth of this plan. 
WHC-SD-WM-CM-011

Rev. 0

\section{CONTENTS}

Executive Summary

Table of Contents

i

Figures:

Figure 1 - Design Reconstitution Program Process 3

Figure 2 - Design Information Summary Development Process 18

Figure 3 - Open and Reconstitution Items Process 23

Table:

Table 1 - Graded Approach for Design Reconstitution Development 11

1.0 INTRODUCTION

1.1 Background

1.2 Purpose

1.3 Design Reconstitution Program Objectives and Benefits

1.4 Terminology and Definitions

2.0 SCOPE 2

2.1 Applicability 2

2.2 Design Reconstitution Program Plan 2

3.0 DESIGN RECONSTITUTION PROGRAM OVERVIEW 2

4.0 INFORMATION RECOVERY AND RECONSTITUTION 6

4.1 Waste Tank System 7

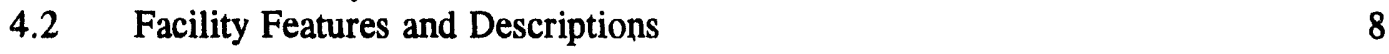

$\begin{array}{lll}5.0 & \text { WASTE TANK FACILITY } & 10\end{array}$

5.1 Watch List Double-Shell and Single-Shell Tanks 10

$\begin{array}{ll}5.2 & \text { Operating Double-Shell Tanks } \\ 5.3 & 10\end{array}$

$\begin{array}{ll}\text { 5.3 Interim Stabilized Single-Shell Tanks } & 10\end{array}$

$\begin{array}{lll}5.4 & \text { Operating Site-Wide Support Systems } & 10\end{array}$

$\begin{array}{ll}5.5 & 12\end{array}$

$\begin{array}{lll}5.6 & \text { Standby Systems } & 12\end{array}$

$\begin{array}{lll}5.7 & \text { Shutdown Systems } & 12\end{array}$

6.0 INFORMATION RECOVERY AND RECONSTITUTION 12

$\begin{array}{lll}6.1 & \text { Background } & 12\end{array}$

$\begin{array}{lll}6.2 & \text { Objectives } & 13\end{array}$

6.3 Technical Documentation Recovery Strategy 13

6.4 Search, Locate, Retrieve, and Identify 14

$\begin{array}{ll}6.5 & 15 \\ 6.6 & \text { Index and Organize }\end{array}$

$\begin{array}{ll}\text { 6.6 Extract Pertinent Information } & 15\end{array}$

6.7 Development of Design Information Summaries 17

$\begin{array}{ll}\text { 6.7.1 Definition } & 17\end{array}$

6.7.2 Types of Design Information Summaries 19

$\begin{array}{ll}\text { 6.7.3 Boundary Identification } & 19\end{array}$

$\begin{array}{lll}\text { 6.7.4 DRPP Pilot Program } & 20\end{array}$ 


\section{CONTENTS (Cont.)}

$\begin{array}{lll}\text { 6.7.5 Priority } & 21\end{array}$

$\begin{array}{ll}6.8 & \text { Verification and Validation } \\ 6.9 & 21\end{array}$

6.9 Identify Design Inputs, Open, and Regeneration Items 21

7.0 TYPES OF SOURCE DOCUMENTS 22

7.1 Government and Industry Codes and Standards 22

$\begin{array}{ll}7.2 & \text { Safety Analysis Documents } \\ 7 & 24\end{array}$

$\begin{array}{ll}7.3 & \text { Operational Safety Documents } \\ 7.4 & 24\end{array}$

$\begin{array}{lll}7.4 & \text { Equipment Lists } & 24\end{array}$

$\begin{array}{ll}7.5 & \text { Functional Design Criteria } \\ 7.6 & 24\end{array}$

7.6 Design Requirements 25

$\begin{array}{ll}7.7 & \text { System Design Descriptions } \\ 77.65\end{array}$

$\begin{array}{ll}7.8 & \text { Design Description }\end{array}$

$\begin{array}{lll}7.9 & \text { Specifications } & 25\end{array}$

$\begin{array}{lll}7.10 & \text { Technical Reports } & 25\end{array}$

$\begin{array}{lll}7.11 & \text { Drawings } & 26\end{array}$

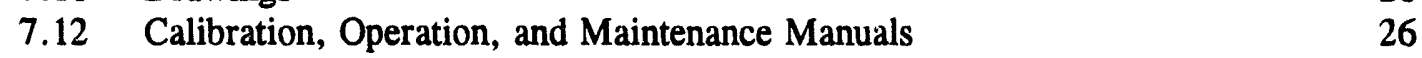

\begin{tabular}{ll}
7.13 & Vendor Information \\
\hline
\end{tabular}

\begin{tabular}{ll}
7.14 & Procedures, Processes and Standards \\
\hline 7
\end{tabular}

\begin{tabular}{ll}
7.15 & Work Packages \\
\hline
\end{tabular}

\begin{tabular}{ll}
7.16 & Engineering Change Notice \\
\hline 7.17 & 27
\end{tabular}

\begin{tabular}{ll}
7.17 & Document Changes \\
\hline
\end{tabular}

$\begin{array}{ll}7.18 & \text { Nonconformances } \\ 7 & 27\end{array}$

7.19 Quality Assurance and Quality Control Documents 28

$\begin{array}{ll}7.20 & \text { Other Documentation } \\ \end{array}$

8.0 INTERFACE MANAGEMENT 28

$\begin{array}{llr}9.0 & \text { TRAINING } & 29\end{array}$

$\begin{array}{lll}10.0 & \text { QUALITY ASSURANCE } & 29\end{array}$

11.0 DESIGN INFORMATION SUMMARIES MAINTENANCE AND CONTROL 29

$\begin{array}{llr}12.0 & \text { REFERENCES } & 30\end{array}$

$\begin{array}{ll}\text { Appendix A - Acronyms } & 31\end{array}$

Appendix B - Glossary $\quad 32$

Appendix C - Description of Implementing Procedures $\quad 37$

Appendix D - List of Document Types $\quad 60$

Appendix E - List of Design Information Summary Titles $\quad 61$

$\begin{array}{ll}\text { Appendix F - Action Plan Outline } & 63\end{array}$ 


\subsection{INTRODUCTION}

\subsection{Background}

In November 1993, the Department of Energy (DOE) Standard (Reference 1) for an Operational Configurational Management Program (OCMP) for existing DOE facilities was issued. This DOE Standard presents recommended configuration management practices and includes adjunct provisions for a Design Reconstitution Program and a Material Condition and Aging Program. The Department of Energy, Richland Operations (DOE-RL) will implement the Hanford site OCMP through their agent Westinghouse Hanford Company (WHC), including the two adjunct programs for the Hanford waste storage tank farms facility.

\subsection{Purpose}

This document provides the Design Reconstitution Program Plan (DRPP) portion of the OCMP for the Hanford waste storage tank farms and their ancillary systems. This reconstitution plan conforms with the intent and guidelines of the OCMP DOE Standard and is an outgrowth and subordinate to the Configuration Management Plan (CMP) for the Waste Tank Farms and 242-A Evaporator (WTF\&E) (Reference 2).

\subsection{Design Reconstitution Program Objectives and Benefits}

The primary DRPP objective is to provide or reconstitute technical baselines for the tank farms facilities as part of the Design Reconstitution Adjunct Program and to document these technical baselines via Design Information Summary (DIS) documents. The deliverables from the DRPP are DISs for the waste tank farms and their ancillary systems. These DISs document the technical baselines for the CMP for Waste Tank Farms and the 242-A Evaporator (Reference 2). Also, these DISs are available to provide technical support for engineering evaluations and studies, tank farm operations, and training. The objectives and benetits follow:

- Encapsulate the design history.

- $\quad$ Provide a necessary technical baseline for tank farms configuration management.

- Provide a comprehensive, reliable, and retrievable design basis information source.

- $\quad$ Provide verified source documentation used for maintaining conformance with the design basis and to generate or evaluate design modifications.

- $\quad$ Provide source documentation useful in conjunction with the Safety Analysis Report (SAR) for performing safety reviews :o ensure continued operation within safe margins.

- Supplement the technical basis for the waste tank farms Operational Safety Requirements (OSR) and training. 


\subsection{Terminology and Definitions}

Standard terminology and standard definitions are established and maintained under the auspices of the CMP for the Waste Tank Farms and the 242-A Evaporator (Reference 2). For this document, Appendix A provides Standard Definitions and Appendix B provides Acronym terminology. Reference 2 is the parent source of these definitions and terminology which are duplicated and augmented in the appendices for convenience.

\subsection{SCOPE}

\section{$2.1 \quad$ Applicability}

The Design Reconstitution Program (DRP) is presented by the DOE OCMP Standard (Reference 1) and is applicable to the Hanford Waste Storage Tank Farms, and ancillary systems, including evaporators. Therefore, a program plan for this requirement is advanced in the following subsection.

\subsection{Design Reconstitution Program Plan}

Th e scope of this document is to provide the DRPP for the Hanford Waste Storage Tank Farms and their ancillary systems as overviewed in the following Section 3.0.

Also, this DRPP integrates with the Tank Waste Remediation Systems (TWRS) Program Management Plan (Reference 3), and the CMP for Waste Tank Farms and the 242-A Evaporator (Reference 2). It also incorporates the applicable findings presented by recently completed assessments, audits, etc.

\subsection{DESIGN RECONSTITUTION PROGRAM OVERVIEW}

The DRPP mission is to provide or reconstitute technical baselines for the tank farms facilities as part of the Design Reconstitution Adjunct Program and documented via DISs. This DRPP is in response to and in compliance with the CMP for the Waste Tank Farms and 242-A Evaporator (Reference 2), and also conforms with the DOE OCMP Standard. To accomplish this mission, the DRPP is structured and implemented in accordance with Figure 1.

Figure 1, Design Reconstitution Program Process, programmatically illustrates the DRPP process, associated activities and is described as follows.

\section{- Program Scope}

The scope is to provide the DRPP for the following:

- Waste storage tank farms equipment

- Ancillary or supporting systems equipment

- Evaporators equipment 


\section{Flgure 1 - Design Reconstitution Program Process}

Rev.0

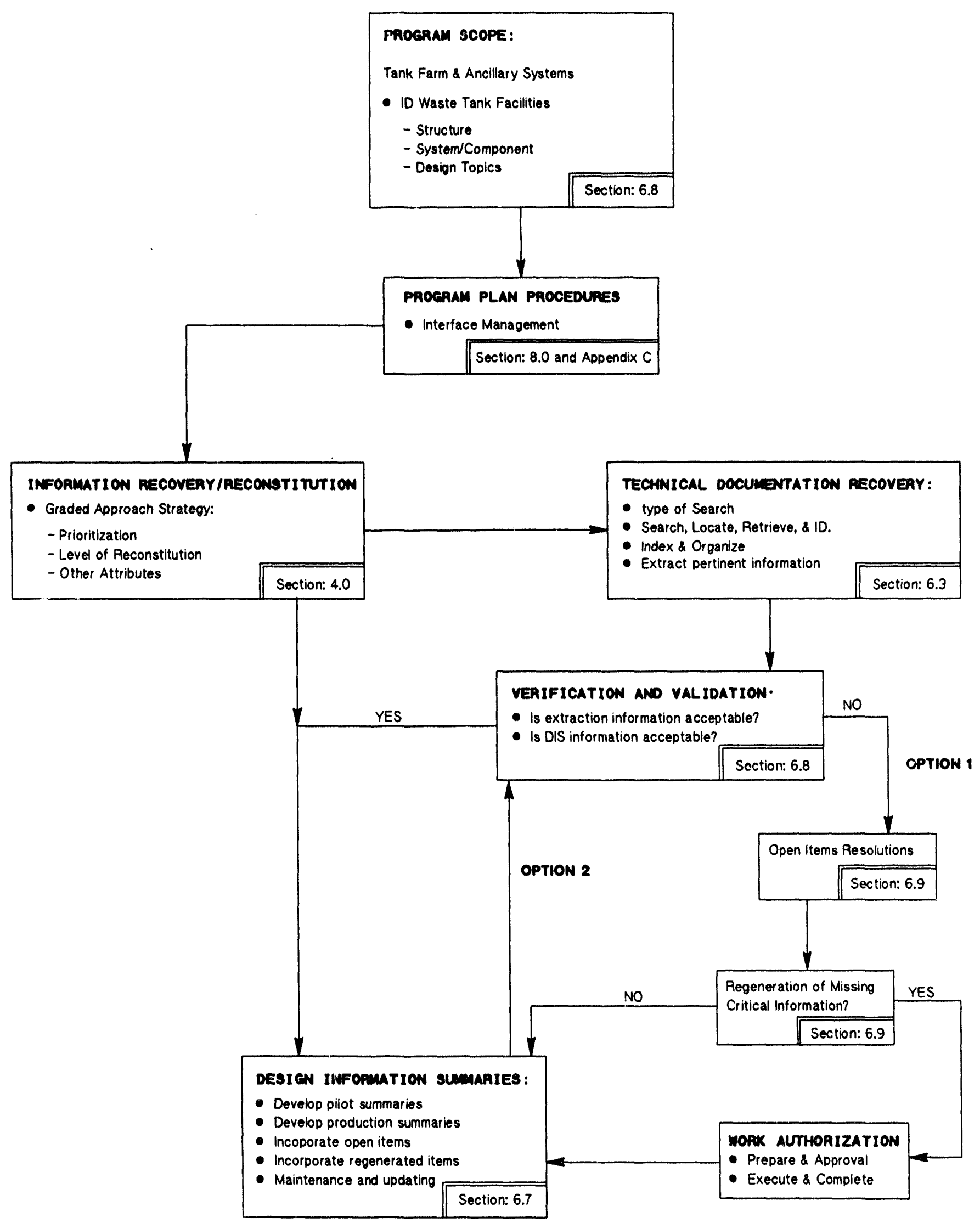




\section{- Program Plan Procedures}

Procedures or guides to implement and effectively manage the DRPP, and to ensure integration with the Reference $2 \mathrm{CMP}$, and for interface management with in place WHC organizations, procedures, and standards are required and will be developed. This results in three procedures and one guide which are introduced throughout the DRPP and described in Appendix C. Interface management is discussed in Section 8.0. The DRPP implementing documents to be developed follow:

- Source Documents Recovery Procedure

- Writer's Guide for Design Information Summaries

- Disposition of Open or Regeneration Items Procedure

- Interface Management Procedure

- Graded Approach Strategy

The application of a graded approach to the tank farms facility entails two steps for each structure, system, or component (SSC). First, the CMP for WTF\&E (Reference 2) provides a prioritized list of SSCs and associated technical input (i.e., design input document types) for further refinement by the DRPP grading approach. For the second step, the DRPP grading approach, which is discussed in Section 4.0, determines for those prioritized SSCs the depth of documentation recovery and the level of content for each DIS. Also, Section 4.0 addresses grading for topical DISs and for the level of reconstitution for open and regenerated items.

- Recovery of Source Documents

Sources of technical information, known as design inputs, reside at the numerous site-wide information repositories. From technical documentation recovered from these repositories, pertinent design information is extracted, evaluated, and then utilized to develop DISs. These DISs are structured documents which organize and consolidate design basis and design requirements information.

- Verification and Validation

The quality of all recovered design input information is required to be evaluated to sanction confirmation. Verification entails the process of checking that a retrieved DIS design input has been completely and accurately translated from its source document. Whereas, validation is the process of providing reasonable assurance that the retrieved design input is reasonable, applicable, and technically appropriate as described. Verification and validation are defined and discussed in subsection 6.8. 
- Open Items Resolutions

Uncertain, conflicting, inadequate, or missing design input information discovered during the DIS development process is either identified as an open item or declared a regeneration item for critical information. Recognize that open items may be recovered at either of two stages in the DIS development process, e.g., (1) during the verification and validation (V\&V) of design inputs at the source documents evaluation stage, or (2) after the DIS preparation stage. These two stages are given by Option 1 and Option 2, respectively on Figure 1 and described in subsection 6.9.

- Regeneration of Missing Critical Information

Open items that are determined to address critical information are promptly elevated to regeneration status. In some cases, the nature or magnitude of regenerating missing or inadequate critical design input information may require that a work authorization be prepared to budget and schedule the resources required to regenerate essential and critical information.

- Design Information Summaries

The Plant Engineering organization is the Design Authority, originator, and primary user of the DISs. Plant Engineering has the option to delegate Design Authority and DIS development to another organization(s) or subcontractor(s). The DISs are documents developed to provide all users with a single source of technical baseline information. This baseline information is essential to support the ongoing safe operation, modification, or maintenance of the tank farm facility. Also, this information is useful for decommissioning planning.

At the outset, several DRPP pilot program DIS documents will be prepared that best represent the tank farms facility. Experiences or "lesson learned" from the DRPP pilot program will be incorporated into the DRPP, implementing procedures, and guide to facilitate process improvements. Also, the DRPP pilot program features a test of incorporating open items and regenerated items that result in revised DISs. This inherently invokes testing the WHC in place procedures for revising DIS documents per Section 11.0.

Design Information Summary documents are estimated to include the following types:

- 20 Structure/System

- 5 Component

- 5 Design Topic 
- Work Authorization

The regeneration of missing or inadequate critical design input information is administrated by a work authorization or a desk instruction device such as an Engineering Task Plan (ETP). This work authorization is required to commit, budget, and schedule the resources required to regenerate essential and critical information. The review and approval of the work authorization by all interfacing organizations ensures participation and coordination among all the necessary resources.

\subsection{INFORMATION RECOVERY AND RECONSTITUTION}

The DOE Standard suggests a graded approach for implementing an OCMP and its subordinate two adjunct programs. The Standard defines a graded approach as:

"a process by which the level of analysis, documentation, and actions necessary to comply with a requirement are made commensurate with a number of considerations, including: the relative importance to safety, safeguards, and security: the magnitude of any hazard involved: the life-cycle of a facility: the programmatic mission of a facility: the particular characteristics of a facility: and any other relevant factor."

The application of the DRPP graded approach to the Hanford Waste Storage Tank Farms system features a two step approach. First, the CMP for WTF\&E (Reference 2) provides a prioritized list of SSCs and associated technical input (i.e., identification of design input document types) for further refinement by the DRPP grading approach. For the second step, the DRPP grading approach, described hereafter, determines for those prioritized SSCs the depth documentation recovery and the level of content for DISs.

Also, the DRPP grading approach includes grading for topical DISs and for the level of disposition of open items and regeneration items. Procedure 3, Writer's Guide for DISs, Part 4 Graded Approach will be developed to define the detailed process.

The DRPP graded approach process will be initiated after the CMP for WTF\&E provides the following via their graded approach:

- A prioritized list of SSCs

- A list of design input document types "ssociated with each SSC 
The DRPP (Procedure 3, Part 4) will accept this input and then systematically apply the DRPP graded approach to determine the following:

- The depth of documentation retrieval (Section 6.0)

- The type of format for the DISs (Subsection 7.7.2)

Since the CMP for WTF\&E is limited to grading SSCs and documentation, grading attributes are necessary for the grading of the following DRPP created entities:

- Design Topic DISs (Appendix E, Design Topics),

- Open Items from the verification and validation process, and

- Open Items authorized for regeneration

For the previously stated DRPP need, the graded approach (Procedure 3) will be developed considering attributes such as: facility mission, facility life cycle, importance to safety (i.e., Safety Class, etc.), operational status, waste type, design commonality among tank structures and farms, ancillary systems, and cost awareness.

For the purpose of establishing DRPP a graded approach envelop, consider the following grouping of SSCs that are described in the following two subsections and Section 5.0:

- Waste Tank System

- Facility Features and Descriptions

- Waste Tank Facility

\subsection{Waste Tank System}

A waste tank system is considered to include: tank structures, ventilation, ancillary evaporator, monitoring instrumentation, piping, etc. Waste tank structures, instrumentation, and equipment may be either part of one or more waste tank systems. Hereafter this hardware is collectively designated as a SSC whose assemblies comprise a waste tank system. Hanford defines a tank system as:

"a dangerous waste storage or treatment tank and its associated ancillary equipment."

- Safety Importance

This attribute is based on safety importance and it is derived from Reference 5 which, according to DOE Order 5820.2. A, reports Watch List Tanks in accordance with Public Law 101-510, Section 3137. One purpose of this Reference 5 report is to evaluate and then categorize all waste tanks by Safety Importance or concern. 
- Safety Classification

This attribute is based on safety class and in accordance with References 6, 7, and 8, Interim Safety Equipment List (ISEL), assigns a Safety Class of either 1, 2, 3, or Nonsafety Class 4 at SSC levels for single-shell, double-shell, and aging waste facilities. These Safety Classes are defined by Reference 9, Table 1 - WHC Safety Class Criteria, and are titled as follows:

\footnotetext{
- $\quad$ Safety Class 1

- $\quad$ Safety Class 2

- $\quad$ Safety Class 3

- $\quad$ Nonsafety Class 4
}

The following subsection describes some addition attributes or factors that will be considered by Procedure 3, Part 4 Graded Approach.

\subsection{Facility Features and Descriptions}

- Design Commonality

Tank farm facility and systems characteristics are important factors. The extent of design commonality or common mode failure potential among the tank farms and ancillary systems facilitate the sharing of common or very similar attributes and thereby reduce the compilation of redundant design information.

- Facility Status

The status of a facility or SSC is also a grading factor that entails a requirement for accurate and correct design information as part of the reconstitution process. Typically the status of a DOE facility or SSC is resolved to be in either an Operating, Standby, or Shutdown mode. The DOE Standby definition does not exactly correspond to the status designation assigned by Hanford to some single-shell waste storage tanks. These singleshell tanks are classified as Interim Stabilized (IS), a status that closely corresponds to Standby. However, there are waste tank ancillary systems that are in modes that correspond to either Operating, Standby, or Shutdown.

- Safety Importance

This attribute segregates and prioritizes waste tanks and ancillary systems in accordance with the Watch List status, including evaporators as follows:

- Watch List Double-Shell and Single-Shell Tanks

- Operating Double-Shell Tanks

- Interim Stabilized Single-Shell Tanks

- $\quad$ Operating Site-Wide Support Systems

- Operating Evaporator 
- $\quad$ Standby Systems

- $\quad$ Shutdown Systems

\section{- Safety Class}

This attribute results in a grading of the SSCs by Safety Class. All SSCs graded as Safety Class 1, in accordance with Reference 9 and recorded in References 6, 7, and 8 or subsequent updated or final safety analysis reports, are considered within DRPP scope. Safety Class 2 and 3 SSCs may be acknowledged in their respective DIS but their design basis content or regeneration effort is less than that required for Safety Class 1. Also, this attribute applies to the prioritization of all reconstitution efforts.

\section{- Summary}

In summary, the CPM for WTF\&E will provide to the DRPP a priority list of DISs and their associated design documentation types. This is a mandatory input to the DRPP, and in essence will "establish" a (SSC) row entry on Table 1 under the Facility Status column. The DRPP graded approach (via Procedure 3) will determine two horizontal selections on the Table for a particular SSC assigned to a particular Facility Status. These two horizontal entries will specify the level of Documentation Retrieval and type of Design Information Summary format per the DRPP graded approach.

In a similar manner the attributes and factors discussed previously will be used to determine grading via Procedure 3, Part 4 for design topic DISs, open items, and regeneration items.

Table 1 outlines the extent of documentation retrieval options, and types of formats options (i.e., mixed, index, or comprehensive) by Facility Status, and by Safety Class. As explained by footnotes on Table 1 , it is not complete and is included in the DRPP for an example of format and assist in describing the DRPP graded approach. The completed Table 1 will reside in the future Procedure 3, Part 4 Graded Approach. The implementation of the DRPP graded approach will be implemented by a future Procedure 3. Tank farm facility characteristics and descriptions are presented in the following subsections.

It is recognized that other possible categories may be useful, e.g. by farm or potential risk of failure and will be considered if technically feasible. 


\subsection{WASTE TANK FACILITY}

\subsection{Watch List Double-Shell and Single-Shell Tanks}

The Reference 3 report declares that 51 tanks are on the watch list as of the date of the report. These tank structures are potential candidates for 51 DISs. Design Information Summaries are one of the significant deliverables prescribed by this DRPP and are described in detail in subsection 6.7.

In the interest of reducing and eliminating redundancy or repetitious common design information, while maintaining DIS intent, these 51 tanks should be consolidated as much as technically feasible with respect to five basic tank configurations given by Reference 11 and design similarity as follows:

- 75' diameter double-shell tanks

- 75' diameter single-shell tanks

. 75' diameter single-shell tanks

- 75' diameter single-shell tanks

- 20' diameter single-shell tanks

$$
\begin{gathered}
1,000,000 \text { gallons } \\
1,000,000 \text { gallons } \\
750,000 \text { gallons } \\
500,000 \text { gallons } \\
50,000 \text { gallons }
\end{gathered}
$$

\subsection{Operating Double-Shell Tanks}

Reference 3 reports a list of operating double-shell tanks not on the watch list as of the date of the report. These are potential candidates for DISs. Design Information Summaries are one of the significant deliverables prescribed by this DRPP and described in detail in subsection 6.7.

In the interest of reducing or eliminating redundancy and repetitious common design information for these non-watch list double-shell tanks, while maintaining DIS intent, these DSTs should, as much as technically feasible, be consolidated with DSTs on the Watch List.

\subsection{Interim Stabilized Single-Shell Tanks}

Reference 3 classifies 106 tanks as interim stabilized (IS), and 59 are identified as assumed leakers. This total includes seven tanks that do not meet current established supernatant and interstitial liquid stabilization criteria. However, these tanks did meet the criteria in existence when they were declared (IS). There are 45 single-shell tanks on the Watch List and 19 are IS. These IS SSTs are candidates for DISs.

In the interest of reducing or eliminating redundancy and repetitious common design information for these IS SST, while maintaining DIS intent, tanks should be consolidated with SST on the Watch List to the extent possible.

\section{$5.4 \quad$ Operating Site-Wide Support Systems}

The Reference 5 report lists ancillary or support systems, site-wide, for the Hanford Waste Tank Farm excluding an operating evaporator which is discussed in the next subsection 5.5. 


\begin{tabular}{|c|c|c|c|c|c|c|c|}
\hline \multicolumn{8}{|c|}{$\begin{array}{l}\text { TANK FARMS AND ANCILLARY FACILITIES } \\
\text { TABLE } 1 \text { - GRADED APPROACH FOR DES'GN RECONSTITUTION DEVELOPMENT }\end{array}$} \\
\hline \multirow[b]{2}{*}{$\begin{array}{l}\text { FACILITY } \\
\text { STATUS }\end{array}$} & \multirow[b]{2}{*}{$\begin{array}{c}\text { SAFETY } \\
\text { CLASS }\end{array}$} & \multicolumn{3}{|c|}{ DOCUMENTATION RETRIEVAL } & \multicolumn{3}{|c|}{ DESIGN INFORMATION SUMMARY DEVELOPMENT } \\
\hline & & $\begin{array}{l}\text { FORMAL } \\
\text { REVIEW }\end{array}$ & $\begin{array}{l}\text { SMART } \\
\text { SEARCH }\end{array}$ & $\begin{array}{l}\text { COMPREHENSIVE } \\
\text { SEARCH }\end{array}$ & $\begin{array}{l}\text { COMPREHENSIVE } \\
\text { FORMAT }\end{array}$ & $\begin{array}{c}\text { MIXED } \\
\text { FORMAT }\end{array}$ & $\begin{array}{l}\text { INDEXED } \\
\text { FORMAT }\end{array}$ \\
\hline \multirow{3}{*}{$\begin{array}{l}\text { WATCH LST } \\
\text { DST \& SST }\end{array}$} & 1 & Required & Required & Requires & $\star$ & RECOMMENDED & $\star$ \\
\hline & 2 & Required & Required & Required & & $\star$ & RECOMMEADED \\
\hline & $3 / 4$ & Required & $\star$ & $\star$ & & & $\star$ \\
\hline \multirow{3}{*}{$\begin{array}{c}\text { OPERATION } \\
\text { DST }\end{array}$} & 1 & & & & & & \\
\hline & 2 & & & & & & \\
\hline & $3 / 4$ & & & & & & \\
\hline \multirow{3}{*}{$\begin{array}{c}\text { INTERM } \\
\text { STABLIRED SST }\end{array}$} & 1 & & & & & & \\
\hline & 2 & & & & & & \\
\hline & $3 / 4$ & & & & & & \\
\hline \multirow{3}{*}{$\begin{array}{c}\text { OPERATION } \\
\text { SITE-WDE } \\
\text { SUPPORT SYSTEMS }\end{array}$} & 1 & & & & & & \\
\hline & 2 & & & & & & \\
\hline & 3/4 & & & & & & \\
\hline \multirow{3}{*}{$\begin{array}{l}\text { OPERATING } \\
\text { EVAPORATOR }\end{array}$} & 1 & & & & & & \\
\hline & 2 & & & & & & \\
\hline & $3 / 4$ & & & & & & \\
\hline \multirow{3}{*}{$\begin{array}{l}\text { STANDBY } \\
\text { SYSTEMS }\end{array}$} & 1 & & & & & & \\
\hline & 2 & & & & & & \\
\hline & 3/4 & & & & & & \\
\hline \multirow{3}{*}{$\begin{array}{l}\text { SHUTDOWN } \\
\text { SYSTEMS }\end{array}$} & 1 & & & & & & \\
\hline & 2 & & & & & & \\
\hline & $3 / 4$ & & & & & & \\
\hline
\end{tabular}


Each ancillary system is a candidate for a DIS. In the interest of reducing or eliminating repetitious common design information for ancillary systems, while maintaining DIS intent, these anciliary systems are examined to determine the possibility of consolidation with respect to shared or common design information.

\subsection{Operacing Evaporator}

For the purpose of this plan, evaporator 242-A (i.e., SSC) is assigned a facility status of an Operating Evaporator on Table 1. The Safety Class assigned to this SSC will then assist in determining the level of documentation retrieval and DIS format required for evaporator $242-\Lambda$.

\subsection{Standby Systems}

For the purpose of this plan evaporator 242-S is assigned a facility status of a Standby System on Table 1. The Safety Class assigned to this SSC will then assist in determining the level of documentation retrieval and DIS format required for evaporator 242-S.

\subsection{Shutdown Systems}

For the purpose of this plan evaporator 242-T is assigned a facility status of a Shutdown System on Table 1. The Safety Class assigned to this SSC will then assist in determining the level of documentation retrieval and DIS format required for evaporator 242-T..

\subsection{INFORMATION RECOVERY AND RECONSTITUTION}

\subsection{Background}

Various types of technical documentation capture design information essential to reconstituting the as-designed and as-built configuration of the tank farms and their ancillary systems. This documentation originated at the outset of tank farm development in the early 1940s and continued to be developed as the tank farm facility evolved to its present size and contigurations. Throughout this evolutionary period, several government agencies, numerous contractors, and subcontractors contributed to this technical documentation inventory.

Over these years, it is believed no central point of authority controlled and managed technical documentation. Furthermore, technical information is captured within documentation residing at centralized repositories, personal files, or may even be even undocumented. Also, the documentation is dispersed among several physical locations or among many record cartons or may have departed with the original designer.

However, several ongoing safety-related Tank Waste Remediation Systems (TWRS) initiatives required the identification, retrieval, review, upgrading, or regeneration of certain technical documents. Some of these initiatives are complete, others continue, and additional initiatives are contemplated. These TWRS efforts and recently issued safety-related documents provide signiificant benefits to the required 
front end DRPP recovery of source documents work breakdown that is described in the following subsections.

\section{$6.2 \quad$ Objectives}

The first objective to prepare for DISs development is to conduct a preliminary assessment of Hanford Site tank waste farm technical documentation management practices. The scope of this assessment is limited to the tank farm and its ancillary systems and entails identifying the various search tools available, determining the historical and current indexing methodologies, identifying physical locations and retention media, and understanding the administrative requirements for requesting or for duplicating documents.

After completing the preliminary assessment, the next steps are necessary to recovery soarce documents and are described in the following subsections:

- Technical Documentation Recovery Strategy

- Search, Locate, Retrieve, and Identify

- Index and Organize

- Extract Pertinent Information

- Verification and Validation

- Identify Design Inputs, Open, and Regeneration Items

\subsection{Technical Documentation Recovery Strategy}

Upon completion of the preliminary assessment of the information resource, a level of documentation recovery is established as prescribed by a matrix to be included in future Procedure 1 , Source Documentation Recovery Procedure. For convenience the matrix is duplicated as Table 1 herein.

Initially, the documentation recovery scope focuses on technical documentation pertaining to the DRPP pilot program. Suggested DRPP pilot program DIS subjects will be determined via the Section 4.0 process and should consider one of the following subjects: mechanical system, electrical system, or design topic.

Three levels of search are employed and focused on information recovery that supports the DRPP pilot program development and then later expanded to include the remaining DISs subjects. These levels of search are defined as follows:

\section{- $\quad$ Formal Review}

This level of search entails the identification, retrieval, and review of summary-level design documents that are readily available. For example, this search would include top-level design document such as the Interim Safety Basis, Safety Analysis Reports, Interim Safety Equipment Lists, and Technical Safety Requirements documents. 


\section{- Smart Search}

This level of search entails the identification, retrieval, and review of design documents that most likely capture design requirements. The type of documents most likely to capture design requirements is considered to be design output documents; for example, drawings, specification lists, set points, etc. Also, this search includes documents that capture the asbuilt design.

\section{- Comprehensive Search}

This level of search targets the identification, retrieval, and review of remaining design documents that capture design information. This level includes documents such as design analyses, calculations, correspondence, and vendor information.

\subsection{Search, Locate. Retrieve, and Identify}

For all levels of search, personnel technically acquainted with DIS topics should perform these functions. Searching should use, but not be limited to, the Engineering Release System Database. In accordance with the recovery strategy, the purpose of this step is to search, locate, retrieve, and identify documents that are candidates for embedded design information. The present situation is that this technical documentation is managed under the auspices of in-place governing procedures, standards, and policies listed by the OCMP Document Control element (Reference 1). Therefore, this step should initially consult Reference 1 . To assist in this initial step, Appendix D lists the types of documentation judged to be sources of design input information required to develop all DISs.

Each category of technical documentation (e.g., drawing, ISB, SAR, calculation, work package, specification, process, procedure, purchase requisition, report, correspondence, etc.) is uniquely identified either as part of the original document or is assigned an unique identifier in accordance with the OCMP Document Control element (Reference 1).

Each uniquely identified document should be linked to a SSC or its parent document in accordance with the traceability requirement prescribed by good CM practice. Traceability should be managed under the auspices of the Configuration Management Plan for Waste Tank Farms and the 242-A Evaporators (Reference 2) and implemented via a relational database such as the computerized Master Equipment List (MEL). This linking should capture document hierarchy, i.e., the parent-child relationship and lirking to one or more SSCs. This capability satisfies the OCMP traceability requirement and thereby provides document lineage to ease design reconstitution.

Section 7.0 identifies the types of documentation required to define design basis and to capture the as-built configuration or their technical baseline. These document types are not all inclusive and therefore are augmented as necessary to include other necessary sources of design information. This collection of candidate documents is then available to be indexed and organized. 


\subsection{Index and Organize}

Once candidate technical documents are identified, each document is then reviewed and indered. A prescribed index form (Reference: future Procedure 1, Source Document Recovery Procedure) is prepared to capture the results of indexing. From these index sheets candidate technical documents attributes should be entered into a database to facilitate cataloging, searching, and sorting by SSC, document type, and date.

Candidate documents are then organized into binders by SSC. Within each binder each document type is filed behind a tab; and within each tab section each document is arranged by chronological order.

For cases where it is not practical to duplicate the recovered document (i.e., the voluminous ASME Code, ISB, etc.) Reference to their location is required or only the applicable page(s) is duplicated and inserted in the binder.

Also in cases where more than one DIS subject share a particular candidate technical document, only one binder is required to retain the duplicate. Other binders cross-Reference to the binder retaining the technical document. This technique eliminates duplicating documents hat are common to many DISs.

This compendium of binders become the source for candidate design inputs required to reconstitute the design basis of the SSCs as culminated by approved and issued DISs. A potential secondary source of design input information is personal contact with the original designer or their associates, if available. This compendium represents the entire (recovered) reservoir of information that Plant Engineering or its designated agent has available to proceed with systematically developing DISs. The next step is discover and extract pertinent information.

As an alternate to the above, WHC emerging technologies may provide electronic copies of source documents sorted by (electronic) binders. The status and applicability of this technology will be explored and considered by future Procedure 1, Source Documents Recovery Procedure.

\subsection{Extract Pertinent Information}

There are two options available with respect to the most effective method to extract pertinent design information from candidate documents.

Option 1 extracts and evaluates pertinent design input information during the recovery of source documents process and prior to initiating the preparation of the DIS. This is the option described by the DOE Standard (Reference 1). Option 2 extracts pertinent information in parallel with the preparation of the DIS and then evaluates pertinent information as a integral part of the verification and validation of . the complete DIS. This plan offers both options as follows.

\section{- Option 1-Recovery of Source Documents}


Technical personnel very familiar with specific SSCs technology and terminology or the DIS author will peruse DIS-specific binders that contain candidate documents for embedded pertinent information. This design information may reside within a document or be distributed among several documents. This pertinent information is extracted or identified by annotation for concurrent verification and validation $(V \& V)$ in accordance with subsection 6.8 .

This perusal process should result in one of the following cases:

- The candidate document is determined to be out of scope and therefore no further evaluation is required. This determination is documented on an index form (Reference: subsection 6.5).

- The candidate document is determined to be in scope but does not capture either pertinent information, or is outdated, or is duplicate information; therefore, no further evaluation is required. This determination is documented on an index form (Reference: subsection 6.5).

- The can lidate document is in scope and captures pertinent design information of unknown confirmation. The discovered design input information is then $\mathrm{V} \& \mathrm{~V}$ as described by subsection 6.8. Design input information that is declared $V \& V$ confirmed is then available for preparing the DIS. If V\&V confirmation of design input information is not accomplished then the design input information that is missing, conflicting, or inadequate is considered for regeneration.

\section{- Option 1 Benefits}

The benefit of this option is that candidate documents can be reviewed in parallel by one or more reviewers. Each reviewer would then perform the V\&V process. Pertinent information that is V\&V confirmed would then be forwarded to the DIS author and thereby relieve the DIS author of this function during preparation of the DIS. This V\&V design input would facilitate and significantly reduce the effort required to verify the complete DIS. Also, the regeneration requirements, if any, are known prior to initiating DIS preparation.

Finally, this option has the benefit of limiting the V\&V of the complete DIS to aspects not discovered (by the technical personnel) during the $V \& V$ of pertinent information extracted from candidate documents.

However, the V\&V reviewer(s) will be required to have an assortment of specialized technical knowledge to cover the range of pertinent information discovered. Also there 
may be considerable risk of counter-productivity in that some V\&V items may be not be required to be included in the DIS or items that are V\&V confirmed are found to be superseded or duplicates.

- Option 2 - Development

Binders that retain candidate documents for a specific DIS are provided to the DIS author(s). For this option, the author(s) extracts pertinent information from the candidate documents in conjunction with the preparation of the DIS. Next, V\&V of pertinent information utilized and distributed throughout the complete DIS is performed as an integral part of the V\&V of the complete DIS. Hence, this option isolates the V\&V process to a completed DIS only.

- Option 2 Benefits

Historically for commercial nuclear design basis programs, one person usually known as a verifier performs only the verification portion of the DIS V\&V process. Hence, validation is not typically performed for commercial nuclear design basis programs due to cost constraints, etc. However, for this plan validation is required.

The DIS verifier has the benefit of evaluating the integration of all design aspects (i.e., reviewing a completed DIS), access to all References that were considered or used, and has a complete DIS document which should enhance and simplify understandings and interfaces. Also, this option eliminates counter productivity in that only those items included in the completed DIS are V\&V.

\subsection{Development of Design Information Summaries}

Figure 2, Design Information Summary Development Process, illustrates that DIS documents are central to implementing the DRPP. The OCMP is the initiating authority. An outgrowth of the OCMP and its adjunct program is the DRPP. The DRPP is implemented via three procedures and a guide that results in a compendium of DISs (i.e., approximately 30 documents).

\subsubsection{Definition}

A Design Information Summary document is defined by the DOE Standard as:

"a summary design document, organized by system or topical area, that provides both the associated design requirements and their design basis." The design requirements provide the result of the design process, and explains why a design requirement has been specified a particular manner or a as a particular value." 
Figure 2 - Design Information Summary Development Process

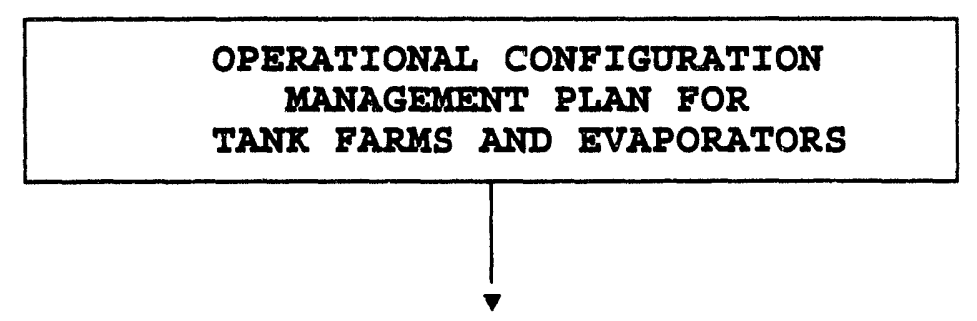

\section{DESIGN RECONSTITUTION ADJUNCT PROGRAM} FOR WASTE TANR FARMS FACILITY
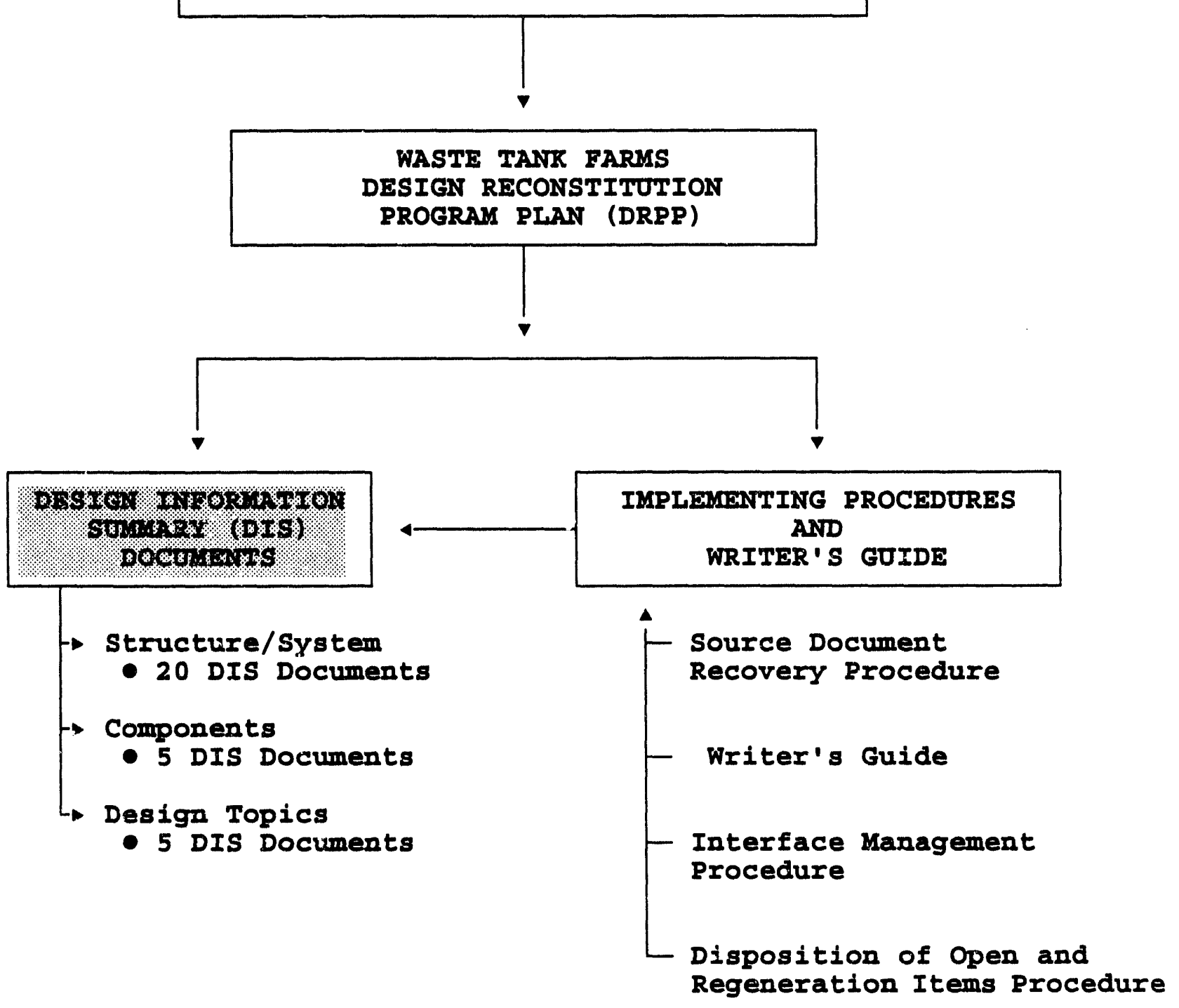
The owner of each DIS is the Plant Engineering organization or any organization designated by Plant Engineering. Plant Engineering is the organization responsible for establishing the design requirements and ensuring that design output documents appropriately and accurately reflect the design basis and as-built configuration.

The objectives of this DRPP are to retrieve, organize, evaluate, and capture existing design information, and to identify and prioritize non-existing design information with an awareness that some existing design information may be found to be inadequate. The results of these objectives are captured via the systematic development of a compendium of DISs and an attendant methodology to reconstitute non-existing or inadequate design information and to disposition open items. The titles for the compendium of DISs are listed in Appendix E and are supported by the MEL.

\subsubsection{Types of Design Information Summaries}

In accordance with the Reference 1 guide, DIS documents can be formatted into three basic types of documents. The waste tank farms facility formats will be established by future Procedure 3, Writer's Guide for Design Information Summaries, which incorporates the applicable features of the three basic types and consistent with the graded approach criteria. The DIS formats will specified by the Procedure 3 and developed as driven by Reference 1, Appendix II-D Content of Design Information Summaries. These basic DIS types are:

- $\quad \underline{\text { Mixed }}$

In general, this type of format is recommended for most of the DIS subjects listed by Appendix E. This format entails descriptive text and the identification of extensive References. Typically, the mixed approach may include the text discussing design bases, supporting design information, and SSC descriptions with Reference to calculations, specification, codes and standards, and other related documents.

- $\underline{\text { Index }}$

This type of "road map" DIS provides minimal text with an extensive collection of References. These References include system descriptions, calculations, specifications, codes and standards, other related or supporting documents.

\section{- Comprehensive}

This type of DIS provides extensive text on design bases, supporting design information. component information. calculation summaries, related drawings and specifications and codes and standards by Reference, date, and applicability.

\subsubsection{Boundary Identification}

Boundaries are identified for each DIS in order to contain scope, ensure a seamless interface among DISs, and preclude duplication of information. These boundaries are identified with respect to entities that interface externally and internally to the DIS and described as follows. 
- External Boundary

The external boundary or scope for a particular SSC or Topical DIS (e.g., fire protection, environmental qualification, seismic, etc.) includes entities related to the DIS subject. For example, adjacent soil, and ambient conditions may be excluded because they are outside the external boundary. However, upon application of the graded approach these subjects may be reconsidered for a design Topical DIS. Future Procedure 3, Writer's Guide for DIS, will establish the DIS subjects and the guidelines for external boundaries.

- Internal Boundary

Within the external boundary, specific physical boundaries for each DIS will be established with respect to support or interfacing systems. These boundaries (e.g., tank ingredients) may be identified by manually annotating "clouds" or "outlines" on the appropriate engineering drawing(s) or by textual description. A DIS subject usually receives "support from" one or more SSCs and provides "support to" one or more SSCs.

Also the internal boundary establishes the level of components in scope. For example, electrical components within a control cabinet (i.e., resistors, solid state devices, connectors, etc.) are out of scope. Similar criterion applies to small size piping, valves, supports, etc. In a manner similar to the external boundary, the internal boundary for each DIS will be established by the future Procedure 3.

\subsubsection{DRPP Pilot Program}

The DRPP pilot program utilizes a vertical and horizontal slice concept. The vertical slice ranges from the recovery of source documents activity through the control, upgrading, and maintenance of the DRPP pilot program DISs, including at least the completion of one open item and one regeneration item. Whereas, the horizontal slice entails a range of DIS subjects e.g., a mechanical, electrical, and topical DIS. In general, the DRPP pilot program should demonstrate significant functional aspects of the following areas:

- DRPP Implementing Procedures/Guide

- Recovery of Source Documents

- Mechanical

- Electrical

- Topical

- Open and Regeneration Items

- Control and Maintenance 


\subsubsection{Priority}

After completion of the DRPP pilot program DISs, the remaining DISs are prioritized in accordance with the graded approach described in Section 4.0. Design Information Summaries priorities are established are part of the DRPP action plan and accomplished in accordance with the implementation procedures and guide.

\subsection{Veritication and Validation (V\&V)}

To establish confirmation, all discovered design inputs are evaluated by the V\&V process in accordance with a to be developed Procedure 2, Disposition of Open or Regeneration Items Procedure.

The DOE Standard detines verification as:

"For the design reconstitution program. the process of checking that the retrieved design information has been completely and accurately translated from the source documents."

The DOE Standard defines validation as:

"For the design reconstitution program. the process of providing reasonable assurance that the retrieved design information is reasonable, applicable, and technically appropriate. This includes determining the appropriateness of analytical methods and technical assumptions."

Upon successful completion of this V\&V process, pertinent design input information that resides within a document or is embedded among several documents is confirmed as a design input for DIS development.

However, any pertinent design information determined to be inadequate, or conflicting, or missing is dispositioned in accord with subsection 6.9 that follows.

Finally, it should be recognized that V\&V of each completed DIS or revision to a DIS is required as prescribed by Option 2 . However, Option 2 should take advantage and benefit from V\&V performed at the time the source document pertinent information was contirmed as prescribed by Option 1. Also, Option 2 facilitates concentration on the integrated effects of design inputs that comprise a DIS.

\subsection{Identify Design Inputs, Open, and Regeneration Items}

Pertinent information that resides within a document or embedded among several documents declared to be inadequate, or conflicting, or missing is evaluated for dispositioning as either an open or reconstituted (i.e., regenerated) item. Future Procedure 2, Disposition of Open or Regeneration of Items Procedure, will specify this process in detail. The range of effort to disposition an open item may range from a simple editorial correction to the regeneration of a comprehensive analysis. 
Upon completion of this disposition or regeneration task and the V\&V processes, the result is then confirmed as a design input for the preparation of a DIS or the revision of an issued DIS.

Design inputs to the DIS originate from two avenues. The first is directly from the source documents after V\&V confirmation. The second avenue is from the disposition of an open item or the completion of a regeneration item. Hence, these inputs which are the results of the previous subsections are then captured by the systematic development (Reference: Procedure 3, Writer's Guide for Design Information Summaries) of a compendium DISs. Titles for the compendium of DISs are listed in Appendix E.

It should be recognized that open and regeneration items could be covered during the preparation of the DIS by the DIS author. These would be treated just like they originated from the source document evaluation for embedded pertinent design information.

During the process of either extracting pertinent information from recovered source documents (see subsection 6.6, Option 1) or V\&V of a completed DIS (see subsection 6.6, Option 2) missing, conflicting, or inadequate design information will be discovered. These findings are usually identified as open items. Open items can range in importance from something very simple and non-safety threatening to a significant item that requires either urgent attention and is a major task and has potentially a short term or long term adverse safety impact.

Figure 3, Open and Reconstitution Items Process illustrates the logic employed to disposition open items. Procedure 2, Disposition of Open or Regeneration Items Procedure, develops the Figure 3 process, logic, grading criteria, and division of responsibilities. This procedure will also include all aspects of the V\&V function which is a required precursor for the disposition of open items.

\subsection{TYPES OF SOURCE DOCUMENTS}

The following subsections list and describe the typical types of government, industry, and Hanford originated documents believed to capture design information. The actual types of documents to be recovered are to be determined by the CMP for Waste Tank Farms and the 242-A Evaporator (Reference 2) or the Design Authority. These documents are recovered and managed in accordance with a to be developed Procedure 1, Source Documents Recovery Procedure.

\subsection{Government and Industry Codes and Standards}

All applicable government and industry regulations, codes, standards, and directives in effect during the five decades of tank farm evolution are intormation sources. These code and standards are identified chronologically by future Procedure 3, Writer's Guide for DISs. 
Figure 3 - Open and Reconstitution Items Process

Rev. 0

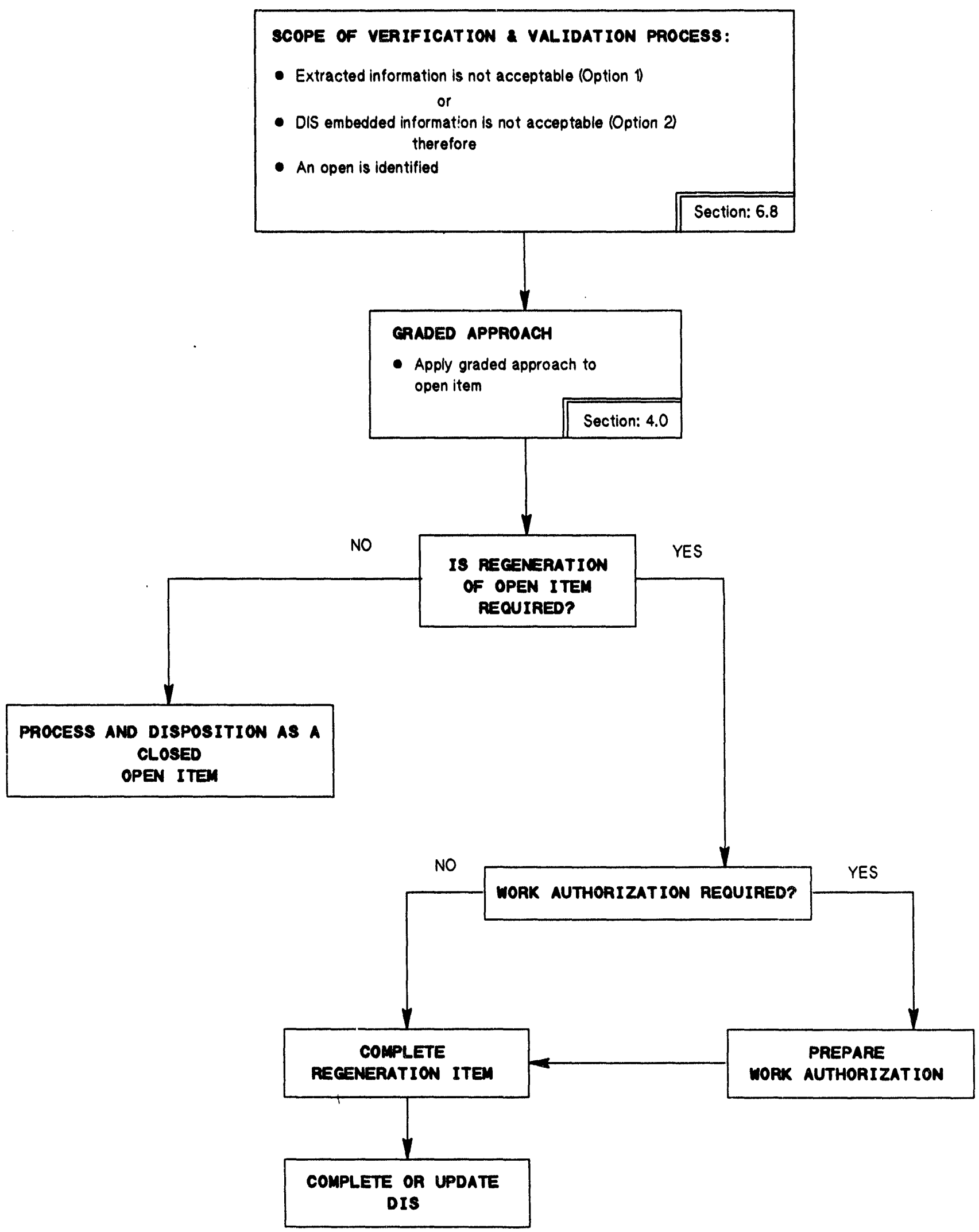




\subsection{Safety Analysis Documents}

The typical type of safety analyses documents are:

- Interim Safety Basis

- Accelerated Safety Basis

- Safety Analysis Report

\subsection{Operational Safety Documents}

The typical type of operational safety document with scope are:

- Operational Safety Requirements

- Operational Safety Directives

- Safety Assessments

- Environmental Assessments

\subsection{Equipment Lists}

The typical type of equipment lists within scope are:

- Safety Envelope Reference List

- Safety Equipment List

- Interim Safety Equipment List

- Supplementary Reference List

- Spares Multiple Unit Listing

- Interface Control List

- Master Equipment List

\subsection{Functional Design Criteria}

Functional Design Criteria (FDC) are technical documents prepared before the definitive design for new SSCs or changes are made to SSCs. Many of the waste farms and ancillary systems pre-date the issue of government orders that currently require the preparation of FDC. Therefore, FDC were only prepared for some of the most recently installed SSCs. Furthermore, it is uncertain that FDC for all SSCs are available or were ever formally issued.

Typically, FDC are expected to include the following categories of information:

- General Requirements

- Facilities Requirement and Criteria

- Structures Requirements and Criteria

- Systems Requirements and Criteria

- Configuration Requirements

- Utilities Requirements

- Instrumentation Requirements

- Design Loads and Demands Including Natural Phenomena

- Safety Requirements

- Applicable Regulations, Codes, and Standards 


\subsection{Design Requirements}

Design Requirements documents define the principle design requirements for the tank farm facility necessary to accomplish the mission statement, consistent with the design approach that has been adopted, and in sufficient detail to permit the definition and allocation of requirements for the tank farm SSCs.

\subsection{System Desion Descriptions}

System Design Descriptions (SDDs) provide tank farm systems design functions, requirements, and purpose, and cuss how these requirements are satisfied by the design. Requirements defined by the SDDs are allocated from the tank farm Design Requirements and Design Descriptions documents.

\subsection{Design Description}

The tank farm SSC Design Description were prepared in accordance with the system design requirements and primary mission of the tank farm facility. It provides an overview of the relationship and interfaces of the various systems, structures, and facilities which comprise the tank farm facility. In addition, design descriptions present a concise summary of the design and the principle parameters of the overall tank farm, and a definition of its individual systems, facilities, and services. Tank farm design descriptions are updated by the cognizant DIS Design Authority, i.e., Plant Engineering, to capture the current as-built and approved technical baseline as impacted by the reconstitution program and physical walkdowns.

\subsection{Specifications}

Equipment or hardware specifications provide the detailed descriptions of engineered components required to procure an item. Facility specifications are the detailed descriptions for site definition, construction, and installation interfaces or access spaces. This includes the following types:

- Equipment Specification

- Operating Specification

- Construction Specification

- Procurement Specification

- Test Procedures/Specification

- Process Specification

\subsection{Technical Reports}

Various technical reports provide analyses records of the results of tasks performed to analyze, evaluate, or assess the functional and physical characteristics of the Configuration Items. This reports are originated by the Plant Engineering, design subcontractors or other WHC OCMP participants. Design analysis documentation is used to establish the WHC OCMP design basis. Technical reports include calculations. Typical categories for this type of information source follows:
- Conceptual Design Report
- Seismic/Stress Analysis
- Stress/Design Report
- Calculations 


\subsection{Drawings}

Drawings typically consist of the following:

- Eacility Architect-Engineer (A-E) Drawings

These information scurces are construction type drawings (and specifications) required to define, operate, and life manage the tank farm facility.

- System Drawings

These information sources are the drawings required to define the end-to-end configuration of systems installed in the WHC OCMP facility. Installation drawings show equipment installed by facility location or area, and usually do not show equipment installed in its system configuration. System drawings show pieces of equipment installed and connected, and are necessary for a complete understanding of system operation and maintenance requirements.

- Equipment Drawings

These information sources are drawings (and specifications) required to define, procure, modify, install, and test specific items that, when assembled, make up the systems installed and connected to constitute the tank farm facility.

- Interface Drawings

Interface drawings control the configuration of items which share an interface. Drawings consulted in conjunction with other interface control documentation that govern or capture the attributes of a common boundary or interface.

Interfaces management is accomplished via the identification and creation of interface control documents for interfaces or common boundaries between systems, parts, processes, etc. It is anticipated that a configured item list will be generated and maintained by the OCMP database.

- Qther Drawings

- $\quad$ IEFD Drawings

- $\quad$ Electric Circuit

- Instrumentation

- Transfer System

\subsection{Calibration. Operation, and Maintenance Manuals}

Calibration, operation, and maintenance manuals, and the process control manual capture the physical and functional requirements developed by the design organizations during design efforts. In addition documents such as instrument loop diagrams, logic diagrams and termination lists were 
developed. These documents are imposed on the tank farm facility operators as system requirements, constraints or as mandatory operation and maintenance parameters, setpoints, and limits.

\subsection{Vendor Information}

Vendor information consists of shop and fabrication drawings, specification sheets, processes, procedures, acceptance testing, inspection reports, operating and maintenance instructions, user's manuals, training materials, warranties, and spare parts recommendations. Also, any other vendor originated information identified as a deliverable by the procurement contract is considered vendor information.

\subsection{Procedures. Processes and Standards}

Fabrication, installation, process, acceptance, test, and operation and maintenance information sources typically reside in the following types of documents:

- Engineering Procedure

- Installation Procedure

- Calibration Procedure

- Operating Instruction

- Operating Procedure

- Maintenance Procedure

\subsection{Work Packages}

Job Control System created work packages are the central source of installation and change control status management and data gathering that captures the as-built configuration.

\subsection{Engineering Change Notice}

Engineering change is a document that when approved is an alteration in an approved configuration of a configured item under development, delivered or to be delivered. An engineering change initiated during installation is typically known as a Field Change. The precursor to an Engineering or Field Change may be either a request or proposal.

\subsection{Document Changes}

Document change is a document that when approved initiates an alteration in an approved and controlled, and distributed document under configuration control and the governing inplace policies, manuals, and procedures per Reference 12. The precursor to an Document Change may be either a request or proposal. This item is sometimes known as a Document Change Notice (DCN).

\subsection{Nonconformances}

Waivers and Deviations are typically considered under the general category of nonconformances. Waivers are departures from approved specifications or drawings that are identified before hardware manufacturing or software coding. Whereas, deviations are initiated to accept an item during 
manufacture, fabrication, assembly, installation, testings, or inspection that departs from specifications or drawings.

\subsection{Quality Assurance and Quality Control Documents}

Inspection Reports, Assessment Reports, Audit Reports, and applicable Quality Assurance (QA) documents are information sources.

\subsection{Other Documentation}

This category includes information sources (i.e., internal and external correspondence, memo, commitments, personal files, databases, etc.) not captured by any of the above types but are required. to ensure technical baseline control. Other documentation would also include data although it may not rigidly fit into design basis documentation (e.g., tank sampling, vapor sampling, photographic characterization, and data collection summaries).

\subsection{INTERFACE MANAGEMENT}

Interface Management is implemented to document, control, and approve configured items interfaces. Configured items were established as part of the Reference 2 CMP. The term "interface" is defined as:

"the functional and physical characteristics required to exist at a common boundary between twe or more functional areas that interact."

In addition, programmatic interface management is required and applied to the interfacing and integrating of the numerous and various plans, programs, change control system, procedures, processes, standards, practices, and systems that constitute the overall OCMP. Procedure 4, Interface Management Procedure, will be developed to describe in detail how to control these interfaces in conjunction with the Reference 2 CMP.

Hence, there are two distinct sectors of Interface Management, i.e., contigured items and programmatic interactions. These two sectors will be controlled by future Procedure 4, Interface Management Procedure. However several interface inputs are noteworthy of mention because they are essential and mandatory keystone inputs to DRPP implementation. These inputs follow:

- Master Equipment List and associated attributes

- Engineering Release System Database (ERSDB)

- The current ongoing physical walkdown task

- The ongoing drawing upgrading task

- Applicable tasks sponsored by the ISB

- Status of CM assessment report recommendations

- Safety analysis report upgrade program

- Interim Safety Equipment List program 
- Tank Farm and Evaporators CMP

- Establish Design Requirements

- Establish Design Basis

- Physical Configuration Assessments

- Databases

- Concepts and Terminology

\subsection{TRAINING}

Document recovery and DIS personnel, management and operating subcontractors, and other specifically designated participants are required to participate in formal training to ensure that the requirements and procedures of this DRPP are understood and properly implemented. Training plans, sessions, and activities are developed, conducted, and recorded in accordance the TWRS Quality Assurance (QA) Program per the following Section 10.0.

\subsection{QUALITY ASSURANCE}

The TWRS Quality Assurance Program as described by Annex 6 of the (RL1994b Program Management System Description (PMSD)) governs all technical and DRPP QA activities.

\subsection{DESIGN INFORMATION SUMMARIES MAINTENANCE AND CONTROL}

Plant Engineering or any designated organization is responsible for DIS preparation, distribution, control, and maintenance in accordance with Reference 12. 
Rev. 0

\subsection{REFERENCES}

1. DOE-STD-1073-93, "Guide for Operational Configuration Management Program, Including the Adjunct Programs of Design Reconstitution and Material Condition and Aging Management," November 1993

2. WHC-SD-WM-CM-008, Configuration Management Plan for Waste Tank Farms and the 242-A Evaporator, of Tank Waste Remediation System (Draft)" June 1994

3. DOE/RL-92-59 (Draft) UC-600, "Tank Waste Remediation System Program Management Plan (PMP)," March 31, 1993

4. WHC-SD-WM-CM-005, List of Structures and System for the Tank Farm and Evaporator Configuration Management Program

5. WHC-EP-0182-66, "Tank Farm Surveillance and Waste Status Summary Report for September 1993," January 1994

6. WHC-SD-WM-SEL-020 Revision 2, "Aging Waste Facility Interim Safety Equipment List, " June 1, 1993

7. WHC-SD-WM-SEL-026 Revision 1, "Double-Shell Tanks Interim Safety Equipment List," June 1, 1993

8. WHC-SD-WM-SEL-027 Revision 1, "Single-Shell Tanks Interim Safety Equipment List," June 1, 1993

9. WHC-CM-1.3, Management Requirements and Procedures, MRP 5.46 Rev.4, "Safety Classifications of Systems, Components, and Structures"

10. NUMARC 90-12, "Design Basis Program Guidelines," October 1990

11. WHC-SD-WM-ISB-001, Vol. 1, Rev. 0, "Interim Safety Basis"

12. WHC-CM-1-1, Management Policies, MP 3.5, "Document Control and Records Management" 
CCB Configuration Control Board

CCP Configuration Control Panel

CI Configuration Item

CM Configuration Management

CMP Configuration Management Plan

DA Design Authority

DCN Document Change Notice

DIS Design Information Summary

DOE Department of Energy

DOE-RL Department of Energy, Richland Office

DR Design Reconstitution

DRPP Design Reconstitution Program Plan

DST Double-Shell Tank

ECN Engineering Change Notice

EDB Equipment Data Base

ETP Engineering Task Plan

FDC Functional Design Criteria

ICD Interface Control Document

ISEL Interim Safety Equipment List

MEL Master Equipment List

M\&O Management and Operating Contractor

PMP Program Management Plan

PMSD Program Management Systems Description

QA Quality Assurance

QC Quality Control

SAR Safety Analysis Report

SC Safety Class

SEL Safety Equipment List

SSC Structure, System, or Component

SDD System Design Description

SEMP System Engineering Management Plan

SST Single-Shell Tank

TWRS Tank Waste Remediation System

V\&V Verification and Validation

WBS Work Breakdown Structure

WHC Westinghouse Hanford Company

WP Work Package

WTF\&E Waste Tank Farms and 242-A Evaporator (WTF\&E) 


\section{Appendix B - Glossary}

As-Built. Documentation (for example, Piping and Instrument Diagrams, and database records) veritied by physical inspection as depicting the actual physical configuration and verified as consistent with the design requirements.

As-Found. Information, often in the form of marked-up documents, that reflects the actual physical configuration and identifies any discrepancies with currently-approved facility documentation.

Assessment. For engineering applications, the process of estimating the value of something using authoritative expert judgement based upon observations of representative cases and rough calculations, rather than determining the exact value based upon comprehensive and detailed examinations, and precise and rigorous complete calculations.

Authorization Basis. Those aspects of the facility design basis relied on by DOE to authorize operation. These aspects are considered to be important to the safety of facility operations. The authorization basis is described in documents such as the facility Safety Analysis Report and other safety analyses, hazard classification documents, the Technical Safety Requirements, DOE-issued safety evaluation reports, and facility-specific cormmitments made in orde: to satisfy DOE Orders or policies. The authorization basis is an important subset of the design basis.

Change. Any alteration or addition, temporary or permanent, to the facility physical configuration, facility documentation, or design requirements. Changes not within current design requirements involve design changes. Identical replacements are not changes.

Change Control. A process that ersures all changes are properly identified, reviewed, approved, implemented, tested, and documented.

Comprehensive Search. A process through which a broad spectrum of documents that may contain design information are identified, retrieved, and evaluated. Key steps involve locating and screening documents that may contain design information and reviewing them to extract design information.

Configuration Management. An integrated management program that establishes consistency and design requirements, physical configuration, and facility documentation, and maintains this consistency throughout the life of the facility as changes occur. The CM program consists of $\mathrm{CM}$ functions associated with the following program elements: program management design requirements, document control, change control, and assessments. The CM program also includes design reconstitution and material condition and aging management as adjunct programs. 
Design Authority. The organization responsible for establishing the design requirements and ensuring that design output documents appropriately and accurately retlect the design basis. The Design Authority is responsible for design control and ultimate technical adequacy of the engineering design process. These responsibilities are applicable whether the process is conducted fully in-house, partially contracted to outside organizations, or fully contracted to outside organizations.

Design Basis. Design basis consists of the design inputs, the design constraints, and the design analysis and calculations. It includes topical areas such as seismic qualification, fire protection, and safe shutdown. The design basis encompasses consideration of such factors as facility availability, facility efficiency, costs, and maintainability, and that subset that relates to safety and the authorization basis. The design basis explains which design requirement has been specified in a particular manner or as a particular value.

Design Documents. Those documents that define either the design requirements or the design basis of the facility. Design documents include design specifications, design change packages, design drawings, design analysis, setpoint calculations, summary design documents, correspondence with DOE that provides design commitments, and other documents that define the facility design.

Design Information. The combination of design requirements and design basis information associated with the design process, consisting of design inputs, design constraints, design analysis and calculations, and design outputs.

Design Information Summary. A summary design document, organized by system or topical area, that provides both the associated design requirements and their design basis.

Design Reconstitution. An adjunct program to the CM program that accomplishes the one-time effort icientifying, retrieving, extracting, evaluating, verifying, validating, and regenerating missing critical design requirements and basis. Design reconstitution encompasses the following functions: developing associated program plans and procedures; identifying and retrieving design information from identified source documents; evaluating, verifying, and validating the design information; resolving discrepancies; regenerating missing critical design information; and preparing and issuing Design Information Summaries.

Design Requirements. Those engineering requirements reflected in design output documents (such as drawings and specifications) that define the functions, capabilities, capacities, physical sizes and dimensions, limits and setpoints, etc. specified by design engineering for a structure, system, and component. The design requirements provide the results of the design process.

Design Requirements Element. A CM program element that encompasses the following functions: establishing and maintaining the facility design requirements, establishing system and process boundaries, assigning structure, systems, and components (SSCs) grades based on the associated design requirements, 
identifying the specific list of SSCs for inclusion in the CM program, an establishing and maintaining the design basis for the design requirements.

Discrepancy. Those open items that are determined to have safety significance.

Document. Recorded information that describes, specifies, reports, certifies, requires, or provides data or results. For the purposes of the CM program, this includes paper copies (procedures, manuals, records, etc.), electronic media (such as word processor files and computer databases), and any other source(s) of information used to design or operate the facility or make sound technical decisions. It includes both current or working documents and historical records. See also "Facility Documents" and "Design Documents."

Document Control. A process that identifies, stores and controls, tracks status especially during revisions, and retrieves documents.

Facility Type and Technical Characteristics. Those considerations related to the particular technical nature of the facility and its design and operating characteristics. These include the facility process and functions, operating conditions, and the nature of hazards involved.

Field Validation. For the design reconstituting program, the process of providing reasonable that design requirements are properly reflected in the physical configuration and in the associated facility documentation. Field validation tests the strength of the basic $\mathrm{CM}$ relationships among design requirements, physical configuration, and facility documentation.

Formal Review. A process through which design information is identified and retrieved from on-toplevel, summary-type design documents such as the Safety Analysis Reports, Technical Safety Requirements, and Safety Design Descriptions.

Graded Approach. A process by which the level of analysis, documentation, and actions necessary to comply with a requirement are made commensurate with a number of considerations, including relative importance to safety, safeguards, and security; the magnitude of any hazard involved; cycle stage of a facility; the programmatic mission of a facility; the particular characteristics of facility; and any other relevant factor.

Horizontal Slice Assessment. An evaluation conducted on a program-by-program basis, such as change control or document control, across various facility systems to determine the effectiveness of the program or procedure. It compares existing program implementation against evaluation and performs an effectiveness review through field evaluations, identifies program strengths and weaknesses, and develops recommendations for program improvement. 
Non-reactor Nuclear Facility. Those activities or operations that involve radioactive and/or fissionable materials in such form and quantity that a nuclear hazard potentially exists to the employees or to the general public. Included are activities or operations that: (1) Produce, process, or store radioactive liquid or solid waste, fissionable materials, or tritium; (2) Conduct separations operations; (3) Conduct irradiated materials inspection, fuel fabrication, decontamination, or recovery operations; (4) Conduct fuel enrichment operations; or (5) Perform environmental remediation or waste management activities involving radioactive materials. Incidental use and generating of radioactive materials in a facility operation (e.g., check and calibration sources, use of radioactive sources in research and experimental and analytical laboratory activities, electron microscopes, and X-ray machines) would not ordinarily require the facility to be included in this definition. Accelerators and reactors and their operations are not included. The application of any rule to a non-reactor nuclear facility shall be applied using a graded approach.

Open Item. A validated situation involving: apparent contradictions from different source documents; concerns; unanswered technical questions; or cases of missing, undocumented, or inaccurate information.

Phased Implementation. Involves establishing priorities, milestones with deliverable products, and implementation schedules within the context of the amount of resources and funding that can reasonably be expected to be available.

Physical Configuration. The actual physical location, arrangement, and material condition of structures, systems, and components within a facility.

Program Management. The process of defining program objectives, identifying actions/tasks to accomplish those objectives, estimating the level of effort needed to complete each task, organizing and scheduling the planned tasks, staffing an organization to accomplish the planned tasks, assigning personnel to specific tasks, monitoring progress during the implementation, identifying problems and taking corrective actions, and recognizing tasks and program completion.

Smart Search. A process through which that set of documents that are most likely to contain design requirements are identified, retrieved and evaluated. Key steps involve location of the source documents most likely to contain design requirements, screening them for applicability, and reviewing them to extract design information.

SSC Grade. A measure of the importance of structures, systems, and components (SSCs) within the facility, based on the most important design requirements applicable to the SSC, that can be used to determine priorities and proper levels of attention and resource allocations. An example of SSC grades and associated priorities is: (1) safety, (2) environmental, (3) mission, and (4) others. 
Structures. Systems, and Components (SSCs). Structures are elements that provide support or enclosure such as buildings, free standing tanks, basins, dikes, and stacks. Systems are collections of components assembled to perform a function such as piping, cable trays, conduit, or HVAC. Components are items of equipment such as pumps, valves, relays, or elements of a larger array such as computer software, lengths of pipe, elbows, or reducers.

Technical Validation. For the design reconstitution program, the process of providing reasonable assurance that the retrieved design information is reasonable, applicable, and technically appropriate. This includes determining the appropriateness of analytical methods and technical assumptions.

Topical Areas. Those topics that involve or affect multiple structures, systems, and components in a facility. Examples include seismic qualification, fire protection, safe shutdown, environmental qualification, electrical separation, and nuclear criticality.

\section{Validation. See "Technical Validation" and "Field Validation."}

Verification. For the design reconstitution program, the process of checking that the retrieved design information has been completely and accurately translated from the source documents.

Vertical Slice Assessment. A top-down evaluation conducted on a system-by-system basis, that assesses each program and process related to the system. It reviews system-related information for consistency, technical adequacy, and completeness; compares design requirements and as-built information; compares physical configuration to associated documentation through walkdowns; identifies strengths and weaknesses; and develops recommendations for improvements.

Walkdowns. A visual inspection of facility structures, systems, and components to identify the as-found physical configuration and any discrepancies with currently approved facility documentation. 
Appendix C - Description of Implementing Procedures

\section{TABLE OF CONTENTS}

Table of Contents

Page

Introduction

Procedure 1. Source Documents Recovery Procedure 40

Procedure 2. Disposition of Open or Regeneration Items Procedure

Part 1: Open Item

Part 2: Regeneration Item

Procedure 3. Writer's Guide for Design Information Summaries

Part 1: Structure/System

Part 2: Components

Part 3: Design Topics

Part 4: Graded Approach

56

Part 5: Verification

58

Part 6: Validation

58

Procedure 4. Interface Management Procedure 


\section{INTRODUCTION}

This document is limited in that it provides only an outline and description of the procedures believed necessary to systematically implement and manage the offered Design Reconstitution Program Plan (DRPP).

It is intended that this information be considered a foundation for developing more comprehensive direction that smoothly integrates with existing WHC business and engineering practices. This information is not all inclusive and significant elements may be have been inadvertently omitted. Also, the ongoing Operational Configuration Management Plan (OCMP) and ensuing procedures could have considerable impact on the structure and content of these procedures. The suggested procedures are the products of several successful commercial nuclear power plant design basis programs.

All implementing devices defined herein should be developed to take full advantage of existing and proven WHC procedures, etc. At the outset, these WHC procedures should be assessed for applicability and then used to the maximum extent, if technically and administratively feasible. This approach should promote integration and seamless interfaces. Also, this tactic should preclude duplication of efforts or conflicting instructions. 


\section{Procedure 1 \\ Source Documents Recovery Procedure}

\section{PURPOSE AND SCOPE}

\section{A. Purpose}

This procedure defines the instructions and methods required to systematically locate, identify, recover, evaluate, categorize, and manage (i.e., technically evaluate) all technical documentation (i.e., source documents with embedded design inputs) necessary to support the development of Design Information Summaries (DIS).

\section{B. Scope}

This procedure encompasses and governs recovery of SSCs and design topics source documents that capture original or design evolution information, and the regulatory commitments necessary to develop DISs.

The OCMP identifies, via a "graded approach," the title and quantity of DISs required for the reconstitution mission. It is suggested that the types of documents in scope be identified by this procedure; however, it is understood that the OCMP has elected to assume this responsibility for reasons unknown to this author.

Hence a question or decision for WHC follows: Might it be more practical, logical, or cost effective for the DRPP to establish the type of document and keep things simple and centralized rather than the OCMP? This WHC decision should be reflected in this procedure. This is one of many interface issues that must be identified and then procedurally resolved. It is also one example of the need for the Interface Management Procedure described by Procedure 4, which would identify, assign, and collect all these interfaces in a single document.

\section{APPROACH}

This procedure considers the following elements that are believed necessary to implement and manage the subject procedure. These elements are not all inclusive and should be augmented or enhanced if required. Also, the sequence of the following elements may require some logical reordering. The steps follow:

1. Appoint a DRPP Project Manager/Lead or a single-point-of-authority to direct the source document recovery activity (i.e., work breakdown task) and subsequent activities. This person should be knowledgeable or become very acquainted with existing WHC procedures and the interworkings of WHC. 
2. Prepare, submit, and obtain approval of the necessary work authorization to fund and schedule the development of this procedure. Ensure that all organizations that ultimately provide support to, or are supported by, this procedure participate in the work authorization process.

3. Select a centralized location dedicated for gathering and retaining hard copy documents and for the document categorization (technical evaluation) activity.

4. Select a "dedicated" database manager (software) to control and administrate document categorization activity and to track the ultimate disposition of every design input document that was technically evaluated. Technical evaluation, for the purpose of this procedure, implies completing a categorization form (i.e, see item 5; and, to be designed as part of this procedure; WNTD has provided an example of this form). It is WHC option to create a DRPP dedicated database or to use an existing (OCMP?) database. Data entry, filing of source documents in binders, and report generation are significant labor intensive activities.

Also, the potential integration of this "source document index" database with future optical disk technology should be acknowledged, considered, and discussed. This database manager should also be capable of automatically publishing, via a report generator, the referenced Section for each DIS.

Please be advised that at this decision point, WHC should decide, if they wish, to ultimately link documents to SSCs, which in CM space is known as "traceability." This procedure should state that it does not address "traceability" and defers this desirable feature to the OCMP. Historically, "traceability" is a significant and required configuration management (CM) feature. It recommended that WHC be fully cognizant of future consequences if traceability is ignored at this time! Backtitting is not recommended because of the level of effort required.

5. Design a document categorization form to extract and capture data field information (e.g., technical keywords, topic, and date only) extracted from the technical evaluation of each source document. The form will also function as a (data) input form to the item 4 database. Extraction of keyword or indexing information SHOULD NOT BE CONFUSED WITH THE EXTRACTION OF DESIGN BASIS (TEXTUAL) INFORMATION WHICH IS PERFORMED BY THE DIS AUTHOR.

6. Assess the applicability and cost effectiveness of pursuing emerging technologies such as optical disk technology, full-text searches, hyperlinking, electronic tiles, work flow, CM, and software package vice a manually propelled hard copy process.

Once a decision is made, then identify the method necessary to collect and organize documents (i.e., affix the completed categorization form?) for use by future DIS authors. Note that these forms could be computer generated and gathered via optical disk 
technology. This partially completed form, (This form will be completed by the DIS author to record the ultimate disposition of the source document, i.e., it is either used as DIS reference, out of scope, or superseded.) and its attached source document are the only output from this procedure and a significant input to Procedure 3. This is another interface that should be recorded by Procedure 4, Interface Management.

Please be advised that documentation collection by either manual (binders) or electronic means should be sorted by SSC, and WHC will have to determine how documents shared by many SSCs are administrated. It should be noted at this point that DIS topics should have been established by the OCMP (note: interface) to drive setting up the binders by SSC and design topic.

Who thinks they have the responsibility to define the DIS DESIGN TOPICS? Is it DRPP, OCMP, or Plant Engineering? This is another example of the importance of Procedure 4, Interface Management.

For the case when several SSCs (or Design Topics) share a single source document, does WHC desire to make a copy for each binder or cross reference each binder that contains a "master copy"? How will WHC identify what binder contains the "master copy"?

7. Identity the human resources and skills required for each document recovery task. An assortment of skills are anticipated that range from clerical to specialized technical expertise.

8. Develop Procedure 1 (Implementing) Action Plan. DO NOT CONFUSE THE PROCEDURE 1 IMPLEMENTING ACTION PLAN WITH THE ATTACHMENT 4 PROGRAMMATIC ACTION PLAN. Define the "division of responsibilities" for this specific procedure that provides the "what, who, and when" and ensure that this plan integrates with the "big picture" OCMP schedule (Note: another required interface for Procedure 4). This action plan is procedure-specific and should be illustrated via a block or flow diagram; and, it could be central to a training program.

9. Develop a training program. The training program should include an extensive discussion on graded approach and how it originates by OCMP and how it relates to safety, SSCs, reconstitution, regeneration items, open items, and task priorities. It appears that each aspect may have a slightly different interpretation and application of a "graded approach." Use tlow diagrams.

10. Obtain approval of Procedure 1 and its Action Plan. Next, occupy the dedicated location and then mobilize staff.

11. Conduct training program. 
12. Implement the Procedure 1 Action Plan. Also, consider a pilot program for inclusion in the action plan.

13. Incorporate feedback or "lessons learned" to fir. tune the procedure or action plan and revise accordingly. Implement the procedure per the Procedure 1 Action Plan (i.e., the production phase).

14. Attempt to describe all the steps on flow, logic, or decision block diagrams.

III. Division of Responsibilities

Based on the above, identify all participating organizations, their specific function(s), and the extent of their support, etc. Their commitment should be ensured via their participation in reviewing and endorsing the work authorization.

IV. Required Inputs (Interface Management)

Identify all inputs required to support this procedure. The organization responsible for each input and its form, fit, or function must be identified and defined to ensure a seamless integration with all DRPP functions and existing WHC procedures. These inputs should be described here and listed in Procedure 4.

V. Required Outputs (Interfaces Management)

Identify all outputs or deliverables generated by the procedure that are required to "feed" other (DRPP, OCMP, etc.) procedure(s) or guide. The organization responsible for each output and its form, fit, or function must be identified and defined to ensure seamless integration with the DRPP, OCMP, etc. These outputs should be described here and listed in Procedure 4 .

VI. References

Cite all WHC existing procedures, references, etc., that are required or consulted. This should also include the future OCMP and its implementing procedures.

VII. Other Details that Should be Specified by the Procedure (Note: The following text was excerpted from the DRPP Rev. B1)

Three levels of search are employed and focused on information recovery that supports the DRPP pilot program development and then later expanded to include the remaining DISs subjects. These levels of search are defined as follows:

- Formal Review

This level of search entails the identification, retrieval, and review of summary-level design documents that are readily available. For example, this search would include top-level design document such as the Interim Safety Basis, Safety Analysis Reports, Interim Safety Equipment Lists, and Technical Safety Requirements documents. 


\section{- Smart Search}

This level of search entails the identification, retrieval, and review of design documents that most likely capture design requirements. The type of documents most likely to capture design requirements is considered to be design output documents; for example, drawings, specification lists, set points, etc. Also, this search includes documents that capture the asbuilt design.

\section{- Comorehensive Search}

This level of search targets the identification, retrieval, and review of remaining design documents that capture design information. This level includes documents such as design analyses, calculations, correspondence, and vendor information.

\section{Search. Locate. Retrieve. and Identify}

Dan Autery's informal report on "where documents reside" should be duplicated in this procedure and existing WHC records management procedures cited as applicable.

For all levels of search, personnel technically acquainted with DIS topics should perform these functions. Searching should use, but not be limited to, the Engineering Release System Database. In accordance with the recovery strategy, this step is to search, locate, retrieve, and identify documents that are candidates for embedded design information.

The present situation is that this technical documentation is managed under the auspices of in-place governing procedures, standards, and policies listed by the OCMP Document Control element (Ref. 1). Therefore, this step should initially consult Ref. 1. To assist in this initial step, Appendix D lists the types of documentation judged to be sources of design input information required to develop all DISs.

Each category of technical documentation (e.g., drawing, ISB, SAR, calculation, work package, specification, process, procedure, purchase requisition, report, correspondence, etc.) is uniquely identified either as part of the original document or is assigned a unique identifier in accordance with the OCMP Document Control element (Ref. 1).

Each uniquely identified document should be linked to an SSC or its parent document, in accordance with the traceability requirement prescribed by good CM practice. Traceability should be managed under the auspices of the Configuration Management Plan for Waste Tank Farms and the 242-A Evaporators (Ref. 2) and implemented via a relational database st 'h as the computerized Master Equipment List (MEL). This linking should capture document hierarchy, i.e., the parent-child relationship and linking to one or more SSCs. This capability satisfies the OCMP traceability requirement and thereby provides document lineage to ease design reconstitution. 
Rev. 0

The procedure should reflect the steps defined in subsection 6.4 through 6.6 of the DRPP Rev. B. A WHC decision is required on what V\&V option to adopt. The option to conduct V\&V after completion of the DIS draft is recommended.

\section{Binder Format}

A description of the format for the binders is required. It is recommended that each binder include a copy of the categorization form and be arranged by SSC or Design Topics, type of document, and date. A code on each categorization form should record that it has been entered into the database. A table of contents for the binder should be computer generated by the database manager. 


\section{Procedure 2}

\section{Disposition of Open or Regeneration Items Procedure}

I. PURPOSE AND SCOPE (Open and Regeneration Items)

\section{A. Purpose}

This procedure defines the instructions and method to systematically grade, prioritize, and process the technical and safety impact of all open items discovered during the development of DISs.

\section{B. Scope}

This procedure will encompass and govern only those open items discovered during the DIS development process.

\section{GENERAL ITEMS to be ADDRESSED by PROCEDURE}

The following should be considered and defined by this procedure. Also please consult Section I, Appendix - Open and Regeneration Items, of Procedure 3.

1. Develop a mechanism (form?) to document and to report an open item. To whom should open items be reported?

2. To prioritize (graded approach?) an open item and to declare it a candidate for regeneration, a criterion, decision process, and responsible organization must be developed and identified. A definition of an open item and regeneration item should be developed. It suggested that all unresolved issues be initially identified as an open items, which are promptly prioritized. After evaluation and prioritization, some issues will remain open items and be a safety concern ranking; whereas other (open items) will be elevated to "regeneration items" status, assigned a safety ranking, and then processed per item 3 and 4 that follows. Because of the anticipated level of concern and effort, this procedure should be divided in parts as follows: Part 1: Open Items and Part 2: Regeneration Items. A logic or decision tree should be crafted for each.

3. Define the process necessary to initiate work authorization to complete a regeneration item.

4. Define the process to request funds for the effort required to disposition open items that are not elevated to regeneration item status.

5. Identify (Note: interface) the computerized system required to track and manage the status of regeneration items and open items. 
6. Develop a format to capture open or regeneration items in a completed DIS for completeness and tracking. For commercial design basis programs, this is typically captured in an appendix and each open item is uniquely identified.

7. Develop a feedback mechanism to revise DISs to incorporate the results of completed or dispositioned open/regeneration items.

8. Develop a logic or decision tree diagram to illustrate this process for this procedure and for a training aid.

9. Create an action plan for Procedure 2.

III. Division of Responsibilities

Based on the above, identify all participating organizations, their specific function(s), and the extent of their support, etc. Their commitment should be ensured by their participation in reviewing and endorsing the work authorization.

IV. Required Inputs (Interface Management)

Identify all inputs required to support this procedure. The organization responsible for each input and its form, fit, or function must be identified and defined to ensure a seamless integration with all DRPP functions and existing WHC procedures. These inputs should be described here and listed in Procedure 4.

V. Required Outputs (Interfaces Management)

Identify all outputs or deliverables generated by the procedure that are required to "feed" other (DRPP, OCMP, etc.) procedure(s) or guide. The organization responsible for each output and its form, fit, or function must be identified and defined to ensure seamless integration with the DRPP, OCMP, etc. These outputs should be descrihed here and listed in Procedure 4.

VI. References

Cite all WHC existing procedures, references, etc., that are required or consulted. This should also include the future OCMP and its implementing procedures. 


\section{Procedure 3}

\section{Writer's Guide for Design Information Summaries}

Part 1: Structure/System

Mechanical SSCs

Electrical SSCs

Part 2: Components

Part 3: Design Topics

Part 4: Graded Approach

Part 5: Verification

Part 6: Validation 


\section{Part 1: Structure/System}

Part 2: Components

(Mechanical SSCs)

I. PURPOSE AND SCOPE (Parts 1 and 2)

\section{A. Purpose}

This guide defines the direction, content, and format required to develop and prepare Mechanical SSC DISs for the WHC WTF\&E as part of the ongoing WHC DRPP. This particular Writer's Guide is structured for Mechanical SSCs that are identified by the WTF\&E CMP graded approach.

\section{B. Scope}

This Writer's Guide describes how to prepare design basis documents (DISs) for the WHC WTF\&E facility. The DISs will be prepared for SSCs per Part 4, Graded Approach of this procedure. The intent of the DISs will be to assist Plant Engineering or the designated Design Authority in making decisions on SSC modifications, to provide background for securing future technical specification relief, to document licensing commitments, to disposition open or regeneration items, to address design changes that are applicable to the SSCs scope, and to provide background information for making safety evaluations consistent with applicable regulatory requirements.

The DISs will describe SSC design bases, including specitic SSC design requirements, interfaces, and accident analysis considerations and assumptions.

\section{DEFINITIONS}

Selected definitions, abbreviations and acronyms to be used in the development of DISs should be originated by the WTF\&E CMP. Definitions are of fundamental importance during the implementation of the DRPP because they reflect the basis to which the WTF\&E facility was licensed, authorized, or approved. Expansion or clarification of these definitions in individual DISs shall be clearly identified in a separate section of each document.

Likewise, the use of abbreviations, and acronyms shall conform to the standard usage as presented by existing WHC standards. Terms that are not defined in WTF\&E, DRPP or DOE Standard OCMP shall be typically spelled out completely each time they are used.

\section{DOCUMENT PREPARATION}

\section{A. Document Sections}

Each Mechanical SSC DIS will be written in six sections and appendixes as follows: 
1.0 INTRODUCTION AND SCOPE

2.0 SSC CONFIGURATION DEVELOPMENT

3.0 SSC LEVEL DESIGN BASIS

3.1 Basic Functions

3.2 Performance Requirements

3.3 External Influences

3.4 Interface Requirements

3.4.1 Supported SSCs

3.4.2 Supporting SSCs

4.0 COMPONENT LEVEL DESIGN BASIS

(This section not required Component DIS)

4.1 Major Components

4.2 Valves

4.3 Instrumentation

5.0 LICENSING COMMITMENTS/REGULATORY COMPLIANCE

6.0 REFERENCES

6.X (List by type of documents)

Appendix A - Calculation Note Summaries (WHC Optional)

Appendix B - Open and Regeneration Items

IV. FORMAT

A. Page Format

Each page of the DIS sections and attachments shall include the following header:

(Upper left corner) (Upper right corner)

WHC WTF\&E Document Number

SSC Title Revision Number

Page Number

B. Body Format

The format for the sections and subsections shall be as follows:

X.0 ALL UPPER CASE AND UNDERLINED

X.1 ALL UPPER CASE

X.1.1 Initially Upper Case

X.1.1.1 Initially Upper Case

C. Cover Sheet

The Cover Sheet shall be prepared according to Exhibit A. The Cover Sheet shall contain the following information:

- Title of Documents 
- Document Identification Number

- Revision Number

D. Record of Revisions

This sheet shall contain a list of revisions to the document including the revision number, date, sequential number of the revision, and pages affected by the revision. (Refer to Exhibit B.) All pages or specific lines on a page affected by the latest revision shall be highlighted in the right-hand margin with a vertical black line.

E. Table of Contents

The Table of Contents shall include the identifying section number, the complete section title spelled out, and the page number.

Subsection topics under major headings (e.g., 1.1, 1.2, etc.) shall be initially capitalized. No further organizational breakdown after the first decimal or degree shall appear in the Table of Contents page.

Both the Cover Sheet and the Record of Revisions shall be listed in the Table of Contents.

A list of tables and figures included in the text portion of the DIS shall appear in sequential order. Each shall be properly identified, and a page number shall be provided for reference.

Appendixes shall be identified and listed as part of the Table of Contents.

\section{F. Abbreviations and Acronyms}

The use of abbreviations and acronyms shall conform to the standard usage as presented by the existing WHC standards. Terms that are not defined in the WTF\&E CMP, DRPP, or DOE Standard OCMP shall be typically spelled out completely each time they are used.

\section{G. Tables and Figures}

Tables and figures will be used to graphically to illustrate selected information referred to in the DIS. Each table and figure shall be numbered consecutively according to their initial reference within each section of the DIS (e.g., the first table referenced will be Table T-1, second will be T-2, etc. Figures will be labelled as Fl, F-2, etc.). The pages of each table and figure shall be consecutively numbered (e.g., the first page of Table T-1 will be T1-1, the second page will be T1-2, etc.).

\section{H. Appendix A - Calculation Summaries (WHC Option)}

This section shall include a statement of purpose for the calculation. It shall summarize the results and state the conclusion. This appendix is a WHC option and could be considered an independent Design Topic DIS. In this case, this section would only reference the Design Topic DIS. 


\section{Appendix B - Open and Regeneration Items}

A listing of all open items or regeneration items discovered during DIS development and preparation activities will be prepared and will be included in Appendix B and transmitted with the DIS. However, open items or regeneration determined critical to the "mission" shall be dispositioned via Part 4, Graded Approach, within a reasonable time after their discovery. Open items and regeneration items will include but not be limited to the following:

1. Unknown sources for design basis statements that have been derived from design output documents such as equipment specifications, system descriptions, SAR, etc.

2. Problems or concerns uncovered during DIS preparation

3. Inconsistencies between applicable design documents (including facility procedures)

4. In-process design changes, studies, and evaluations that may affect design basis

5. Missing or inadequate design input information or documentation.

\section{J. Exhibits}

Prepare examples of Exhibit A (Cover Sheet) and Exhibit B (Revision Sheet). 
Rev. 0

Part 1: Structure/System

Part 2: Components

(Electrical SSCs)

I. PURPOSE AND SCOPE (Parts 1 and 2)

A. Purpose

This guide defines the direction, content and format required to develop and prepare Electrical SSC DISs for the WHC WTF\&E as part of the ongoing WHC DRPP. This particular Writer's Guide is structured for instrumentation and control/electrical SSCs as identified by the WTF\&E CMP graded approach.

B. Scope

This Writer's Guide describes how to prepare Electrical DISs for the WHC WTF\&E facility. The Writer's Guide is applicable to any instrumentation and control (I\&C) and electrical system included as part of the ongoing DIS Program Plan.

For illustration, the examples used for this Writer's Guide are specitic to the a commercial nuclear plant, Reactor Protection System (RPS).

The DISs will be prepared for Electrical SSCs identified via Part 4, Graded Approach of this procedure. The intent of the DISs will be to assist Plant Engineering or the designated Design Authority in making decisions on SSC modifications, to provide background for securing future technical specification relief, to document licensing commitments, to disposition open or regeneration items, to address design changes that are applicable to the SSCs scope, and to provide background information for making safety evaluations consistent with applicable regulatory requirements.

The DISs will describe SSC design bases, including specific SSC requirements, interfaces, and accident analysis considerations and assumptions.

Implementation of the DRPP DIS work breakdown will provide an essential element in supporting the ongoing WTF\&E CMP. This Writer's Guide is a method to ensure fulfilling the DRPP DIS intent for selected SSCs.

II. DEFINITIONS

Same as Mechanical DIS.

III. DOCUMENT PREPARATION

Each Electrical SSC DIS will be written in six sections and appendixes as follows:

\subsection{INTRODUCTION AND SCOPE}




\subsection{SYSTEM CONFIGURATION DEVELOPMENT}

3.0 SYSTEM LEVEL DESIGN BASES

3.1 Basic Functions

3.2 Functional Design Requirements

3.3 External Influences

3.4 Interface Requirements

4.0 SYSTEM COMPLIANCE

5.0 LICENSING COMMITMENTS

6.0 REFERENCES

Appendix A - Calculation Summaries (WHC Optional)

Appendix B - Open and Regeneration Items

IV. FORMAT

A. Page Format

Same as Mechanical DIS.

B. Body Format

Same as Mechanical DIS.

C. Cover Sheet

Same as Mechanical DIS.

D. Record of Revisions

Same as Mechanical DIS

E. Table of Contents

Same as Mechanical DIS.

F. Abbreviations and Acronyms

Same as Mechanical DIS.

G. Table and Figures

Same as Mechanical DIS

H. Appendix A - Calculation Summaries

Same as Mechanical DIS

I. Appendix B - Open and Regeneration Items

Same as Mechanical DIS

J. Exhibits

Same as Mechanical DIS 


\section{GENERAL INFORMATION FOR ELECTRICAL DIS}

\section{A. Section 1-Introduction and Scope}

This section shall contain an overview of the system functions and detine the scope and physical boundaries of the system and its components. Figures shall be provided that portray the system boundaries schematically. Specifically, electrical and I\&C System boundary definitions should include electrical power, signal (input), and control (output) electrical components so that the DIS user fully understands the system scope addressed by the document. Whenever possible, specific components (relays, circuit breakers, signal isolation devices, etc.) should be designated to identify specific system boundaries.

Typical system boundary statements for electrical interfaces are as follows: "For system components receiving electrical power, the system boundary is at the load side of the circuit breaker at the power supply bus component."

I\&C that is necessary for system operation should be included within the system boundary definition.

\section{ACTION PLAN}

Develop an action plan for this procedure. 


\section{Part 3: Design Topics}

\section{PURPOSE AND SCOPE - (Part 3)}

\section{A. Puroose}

This guide defines the direction, content, and format required to develop and prepare Design Topic DISs for the WHC WTF\&E as part of the ongoing WHC DRPP.

\section{B. Scope}

This Writer's Guide describes how to prepare Design Topic DISs for the WHC WTF\&E facility. The DISs will be prepared for design topics identified via Part 4, Graded Approach of this procedure. The intent of the DISs will be to assist Plant Engineering or the designated Design Authority in making decisions on design topic modifications, to provide background for securing future technical specification relief, to document licensing commitments, to disposition open or regeneration items, to address design topic changes that are applicable to design topic scope, and to provide background information for making safety evaluations consistent with applicable regulatory requirements.

A Design Topic DIS shall contain the important information used to develop the safety-related portion, if any, of the licensing basis of the WTF\&E facility or aspects important to safety. The Design Topics DIS may consist of a series of individual design topics or may consist of an independent DIS for each selected design topic.

Implementation of the DRPP DIS work breakdown will provide an essential element in supporting the ongoing WTF\&E CMP. This Writer's Guide is a method to ensure fulfilling the DRPP DIS intent for selected design topic.

\section{DEFINITIONS}

This section remains the same as Mechanical DIS.

\section{DOCUMENT PREPARATION}

\section{A. Document Sections}

Each Design Topic DIS will be written as follows:

This section and the following sections parallel the Mechanical DIS section modified if required and desired. It is suggested that the author of this guide consult NUMARC 90-12, Design Basis Program Guidelines and the DOE-Standard for some insight on DIS content and formats for design topic DIS. 
Part 4: Graded Approach

\section{GENERAL DISCUSSION}

The graded approach procedure should address the following and provide instructions and direction on how to complete Table 1 of the DRPP Rev. B1.

1. The application of the DRPP graded approach to the Hanford Waste Storage Tank Farms system features a two step approach.

- First, the CMP for WTF\&E provides a prioritized list of SSCs and their associated technical inputs (i.e., identification of design input document types for each SSC) for further input and use by DRPP Procedure 1 .

- Second, the DRPP grading approach, described hereafter, determines for the prioritized SSCs the nature and depth of documentation recovery and the level of content for DISs

2. Also, the DRPP graded approach includes grading for Design Topic DISs and for the manner and level of disposition of open items and regeneration items.

3. The DRPP graded approach process will be initiated after the CMP for WTF\&E provides the following inputs via the CMP graded approach:

- A prioritized list of SSCs

- A list of design input type of documents associated with each SSC

4. This procedure will accept this input and then systematically apply the DRPP graded approach to determine the following:

- The depth and nature of documentation recovery (Ref: DRPP Sect. 6.0 of DRPP Rev. B1)

- The type of DIS format (Ref: Subsection 7.7.2 of DRPP Rev. B1)

5. Because the CMP for WTF\&E is limited to grading SSCs and type of documents, grading attributes are necessary for grading of the following DRPP created entities:

- Design Topic DISs (Ret: DRPP Appendix E, Design Topics),

- Open items from the verification and validation process, and

- Open items elevated to regeneration item status 
6. For the previously stated DRPP needs, this procedure (Part 4) should consider attributes such as: facility mission, facility life cycle, importance to safety (i.e., safety class, etc.), operational status, type of waste, design commonality among tank structures and farms, ancillary systems, and cost awareness. Particular attention should be on safety class of components within systems. This will require considerable assistance from John Vann's organization to ensure that all combinations of safety aspects are addressed.

7. For establishing DRPP as a graded approach envelope, consider the following grouping of SSCs:

- Waste Tank System

- Facility Features and Descriptions

- Waste Tank Facility 


\section{Part 5: Verification}

\section{GENERAL DISCUSSION}

The DOE Standard definition should be stated. The verifier should be an independent reviewer of the DIS and not the author. A check list that defines the items or criteria for verification should be created. A graded approach should be considered to contain effort. The verifier should sign the DIS after the author and have access to each and every reference that the author consulted during DIS development. The verifier should also be aware of open and regeneration items status. The author is required to formally respond to each recorded finding or question by the verifier.

Part 6: Validation

\section{GENERAL DISCUSSION}

The DOE Standard definition should be stated. Validation can be considered to be a paper validation or physical validation. Physical validation entails walkdowns or performance testing. The graded approach, taking into consideration reasonableness and technical appropriateness, should be factored into the validation process and criteria. This part of the procedure should be carefully crafted to contain scope and effort. It may be advisable to consult NUMARC 90-12 and inquire about the commercial nuclear power approach to validation.

\section{ACTION PLAN}

Develop an action plan for all six parts of this procedure. 


\section{Procedure 4}

\section{Interface Management Procedure}

\section{SCOPE AND PURPOSE (Interface Management)}

The intent of this procedure is to identify and define all the administrative interface requirements and should address the following elements that are not all inclusive:

1. What inputs are required to DRPP to support its function and purpose?

2. What is the form, fit, and function of these interfaces?

3. What is the form, fit, and function of DRPP outputs to WHC and to the parent CMP?

4. What are the inputs required from each of several CMP elements for DRPP to function?

5. What existing WHC procedures interface with DRPP, and how, and why?

6. How does ongoing TF upgrade activities and analyses interact with the ongoing DIS development? Who, what, where, and when are providing this information?

7. How does DRPP integrate with the overall WHC CMP schedule, if any, and the TF OCMP schedule, if any, and the SEMP?

8. How does DRPP interface with the organizations that have the human resources skills necessary to develop DISs?

9. The DOE Standard should be reviewed in detail and each and every interface identified. It is recommended that a compliance matrix be developed from the DOE Standard and that this procedure define and assign each interface. DRPP depends considerably on an assortment of outputs from various CMP elements Does CMP understand and agree to provide each DRPP input? Now is the time to establish this covenant. 
System Design Descriptions

Functional Design Criteria

General Design Criteria

Operational Safety Requirements

Engineering Drawings

Lists

- Safety Envelope Reference List (SERL)

- Safety Equipment List (SEL)

- Interim Safety Equipment List (ISEL)

- Supplementary Reference List (SRL)

- Master Equipment List (MEL)

- Spares Multiple Unit Listing

- Interface Control List (ICL)

- Configuration Controlled SSCs

Operational Safety Documents

Interim Safety Basis (ISB)

Accelerated Safety Basis (ACB)

Final Safety Analysis Report (FSAR)

Updated Final Safety Analysis Report (UFSAR)

Calculations

Specifications

- Equipment

- Operating

- Construction

- Procurement

- Test

- Process

Government

- Correspondence

- Order

- Standard

- Regulation

- Directive

- Guideline

- Policy

Industrial

- Code

- Standard

- Guideline

- Practice

Drawings

Technical Reports

Internal Correspondence

Vendor Information

Manuals 


\section{Structures}

For the purpose of implementing a graded approach in concert with the WTF\&E CMP graded approach and identifying a candidate list of Design Information Summary documents Hanford waste tanks are considered as structures and are cataloged as follows:
- Watch List Double-Shell Tanks
- Watch List Single-Shell Tanks
- Operating Double-Shell Tanks
- Interim Stabilized Single-Shell Tanks

From the above categorization and other considerations, the following order for organization is offered:
1. Double-Shell Tanks (Watch List) Design Information Summary
2. Single-Shell Tanks (Watch List) Design Information Summary
3. Double-Shell Tanks (Operating) Design Information Summary
4. Single-Shell Tanks (Interim Stabilized) Design Information Summary

\section{Systems}

For the purpose of implementing a graded approach in concert with the WTF\&E CMP graded approach and identifying a candidate list of Design Information Summary documents Hanford ancillary systems are considered as systems and are cataloged as follows:

- Operating Site-Wide Support Systems

5. Waste Transfer System

6. Double-Contained Receiver Tank Ventilation Systems

7. Electrical Power Distribution System

8. Common Site-Wide Instrumentation and Surveillance Monitoring

9. Cathodic Protection System

10. Interlock Systems

11. Water Supply Systems

12. Steam Supply Systems

13. Compressed Air Systems

- Operating Evaporator

14. Evaporator 242-A 
- Standby Systems

15. Evaporator 242-S

- Shutdown Systems

16. Evaporator 242-T

\section{Components}

For the purpose of implementing a graded approach in concert with the WTF\&E CMP graded approach and identifying a candidate list of Design Information Summary documents the following are considered Hanford components and cataloged as follows:

17. Waste Transfer System Components

- Transfer Lines and Jumpers

- Tank Farm Valve Pits

- Double-Contained Receiver Tanks

- Diverter Stations

- Diversion Boxes

- Catch Tanks

- Receiver Vaults

- Pumps and Associated Equipment

\section{Design Topics}

For the purpose of implementing a WTF\&E DRPP (Reference Section 4.0) graded approach and identifying a candidate list of Design Information Summary documenis design topics are cataloged as follows:

13. Waste Transfer System Processing

19. Accident Analysis

20. Equipment Qualification

21. Calculation Summaries

22. Fire Protection System

23. Seismic Qualification

24. Replacement Parts

25. Pipe Break

26. Setpoint Document

26. Vendor Manual Summary

27. Equipment/Traceability Document

28. Excavation, Backfill, and Grading 
The following is a suggested project-level outline for the DRPP action plan.

- Obtain Approval of the DRPP

- Issue Phase 1 DRPP Implementation Work Authorization Request

- Authorization

- Scope and Objectives

- Participating and Responsible Organizations

- Work Breakdowns

- Integration with CMP Schedule (Constraints)

- DRPP Schedule

- Deliverables

- Budget Estimate

- Obtain Approval of Phase 1 DRPP Implementation Work Authorization (WA)

- Execute Phase 1 of DRPP Implementation WA

- Appoint the DRPP Project Manager or Lead

- Complete Orientation and Training Material

- Establish a Working Location

- Mobilize and Staffing

- Conduct Orientation and Training

- Phase 1 - Prepare DRPP Governing Documents in accordance with the detailed outlines. This includes the following four implementing devices:

- Source Documents Recovery Procedure

A Writers' Guide for DISs

- Disposition of Open or Reconstitution Items Procedure

- Interface Management Procedure

- Issue Phase 2 DRPP Implementation WA

- Same contents as Phase 1 WA

- Obtain approval of Phase 2 WA

- Execute Phase 2 DRPP Implementation WA Work Breakdown

- Phase 2 will consist of a pilot part and a production part. At the outset, this entails determining the locations, identification, gathering, evaluation, categorization, and management of design input source documents.

- A pilot project will be implemented to test the process and identify and incorporate process improvements. On completion of the pilot project the production program will be initiated. The outputs of the pilot and production programs will be a source document organized in 
binders or electronically by SSC or design topic for use by each DIS author. The results of the pilot project should be assessed and the procedure improved as required.

- Proceed with the production part of design input source documents recovery WA.

- Issue Phase 3 DRPP Implementation WA

- Obtain approval of Phase 3 WA.

- Phase 3 is a pilot project and entails using the sorted or categorized source documents from the pilot Phase 2 activity and then proceeds with developing several pilot DISs in accordance with the Writer's Guide for DISs. The procedure for the Disposition of Open or Reconstitution Items Procedure should also be tested during this DIS development process. The results of this pilot project should be assessed and procedures improved as required. Also, the WHC existing procedures should tested for controlling and revising the DISs.

- Issue Phase 4 DRPP Implementation WA

- Obtain approval of WA.

- Phase 4 is the production mode and entails using the remaining sorted or categorized source documents from the production Phase 2 project and then proceeds with developing several pilot DIS in accordance with the Writer's Guide for DISs. The procedure for the Disposition of Open or Reconstitution Items Procedure should also be tested during this DIS development process. The results of this pilot project should be assessed and procedures upgraded as required. Also, the WHC existing procedures should be tested for controlling and revising the DIS. 

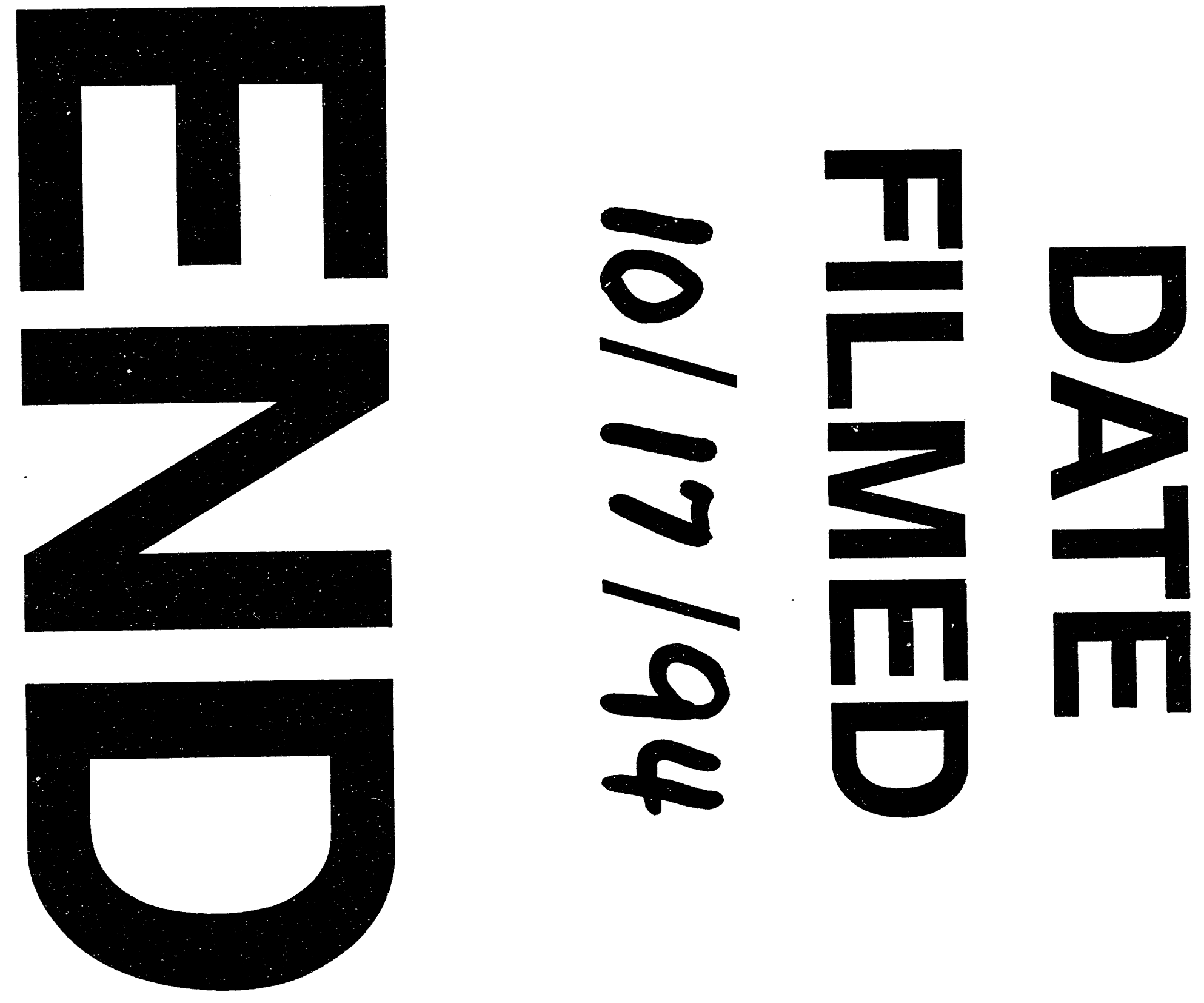
